\title{
Preliminary Assessment of the Hanford Tank Waste Feed Acceptance and Product Qualification Programs
}

\author{
SRNL \\ C.C.Herman \\ D.J.Adamson \\ D.T.Herman \\ D.K. Peeler \\ M.R. Poirier \\ S.H. Reboul \\ M.E.Stone
}

PNNL

R.A. Peterson

J. Chun

J.A. Fort

J.D. Vienna

B.E. Wells

March 2013

Savannah River National Laboratory Savannah River Nuclear Solutions, LLC Aiken. SC 29808
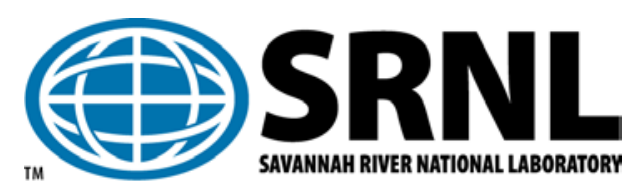

SAVANNAH RIVER NATIONAL LABORATORY
Pacific Northwest National Laboratory P.O. Box 999

Richland, WA 99352

\section{Pacific Northwest}

NATIONAL LABORATORY

Proudly Operated by Battelle Since 1965 
SRNL-STI-2012-00776

PNNL-22116

Revision 0

\section{DISCLAIMER}

This document was prepared in conjunction with work accomplished under Contract No. DEAC09-08SR22470 with the U.S. Department of Energy.

This work was prepared under an agreement with and funded by the U.S. Government. Neither the U. S. Government or its employees, nor any of its contractors, subcontractors or their employees, makes any express or implied: 1 . warranty or assumes any legal liability for the accuracy, completeness, or for the use or results of such use of any information, product, or process disclosed; or 2. representation that such use or results of such use would not infringe privately owned rights; or 3. endorsement or recommendation of any specifically identified commercial product, process, or service. Any views and opinions of authors expressed in this work do not necessarily state or reflect those of the United States Government, or its contractors, or subcontractors.

Printed in the United States of America

Prepared for

U.S. Department of Energy 
SRNL-STI-2012-00776

PNNL-22116

Revision 0

\section{REVIEWS AND APPROVALS}

AUTHORS:

C.C.Merman

C.C. Herman

$2-25-13$

Process Technology Programs

Savannah River National Laboratory

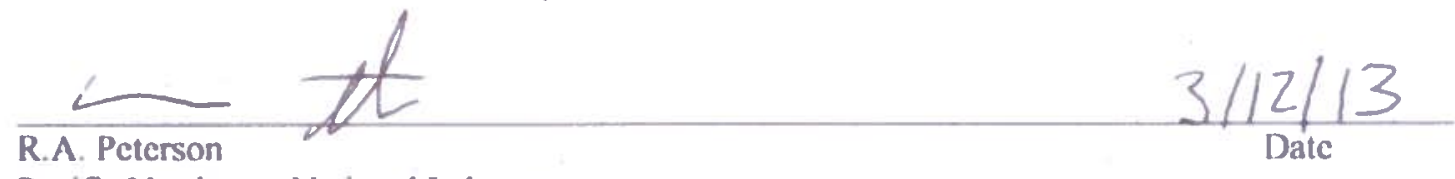

Pacific Northwest National Laboratory

APPROVAL:

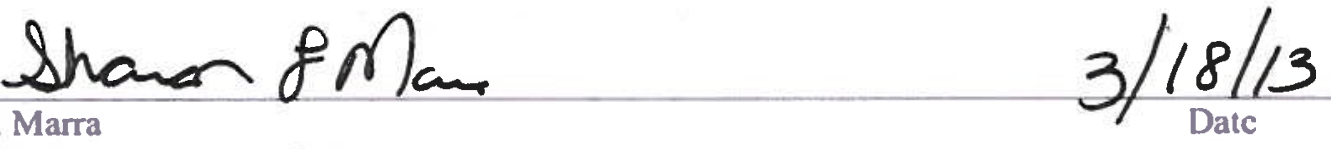

Environmental \& Chemical Process Technology Rescarch Programs

Savannah River National Laboratory

$\Gamma_{\text {P.A. Bredt }}^{3 / 14 / 13}$

Pacific Northwest National Laboratory 


\section{ACKNOWLEDGEMENTS}

The authors would like to thank the following for their contributions to the assessment performed in the WTP Waste Feed Acceptance and Product Qualification area:

- SRNL - Erich Hansen, Ken Imrich, Sharon Marra, and Bill Wilmarth

- PNNL - Phil Gauglitz

- WTP - Aruna Arakali, Peter Benson, Garth Duncan. Jeff Markillie, Jim Nelson, Ivan Papp, and David Reinemann

- WRPS - Stuart Arm, Tom Crawford, Jann Frye, Jacob Reynolds, and Scott Saunders

- ORP - Chris Harrington

- DOE-HQ - Denis Koutsandreas and Nick Machara 


\section{EXECUTIVE SUMMARY}

The U.S. Department of Energy - Office of Environmental Management (EM) has tasked the national laboratories to provide the scientific and technological rigor to support EM program and project planning, technology development and deployment, project execution, and assessment of program outcomes. The Savannah River National Laboratory (SRNL) and Pacific Northwest National Laboratory (PNNL) are coordinating the engagement of the broader national laboratory community to develop and deploy technologies and programs to reduce risk, as well as cost and schedule, in the Hanford tank waste feed acceptance and product qualification area. As a first step, the laboratories examined the technical risks and uncertainties associated with the planned waste feed acceptance and product qualification testing for Hanford tank wastes. Science and technology gaps were identified for work associated with 1) waste feed acceptance criteria development with emphasis on identifying the feed properties and the process requirements, 2) the Tank Waste Treatment and Immobilization Plant (WTP) process qualification program, and 3) the WTP High Level Waste (HLW) glass product qualification program. Opportunities for streamlining the acceptance and qualification programs were also considered in the gap assessment. Technical approaches to address the gaps and/or implement the opportunities were identified. In some cases, the identified gaps or improvement opportunities are currently being worked by the Hanford contractors and a status of those programs is included in the approach for completeness. The approaches will be further refined and developed as strong integrated teams of researchers from national laboratories, contractors, industry, and academia are brought together to provide the best available science and technology solutions.

Pursuing the identified approaches will have immediate and long-term benefits to DOE in reducing risks and uncertainties associated with tank waste removal and preparation, transfers from the tank farm to the WTP, processing within the WTP Pretreatment Facility, and in producing qualified HLW and Low Activity Waste glass products. Additionally, implementation of the identified opportunities provides the potential for long-term cost savings given the anticipated facility life of WTP. A summary of the technology gaps and/or improvement opportunities are provided in the table below.

Revisions to this assessment will be performed as programs are completed by both the laboratories and the contractors providing support to the Hanford Tank Waste Treatment and Immobilization Plant. 
SRNL-STI-2012-00776

PNNL-22116

Revision 0

\begin{tabular}{|c|c|}
\hline Section & Technology Gap/Improvement Opportunity \\
\hline \multirow[t]{5}{*}{3.1 - Understanding Properties of the Feed } & Parameters Controlling Waste Feed Rheology \\
\hline & Particle Size and Density \\
\hline & Critical Velocity \\
\hline & Slurry Abrasivity, Erosion, and Corrosion Assessments \\
\hline & Physical and Chemical Speciation of Plutonium \\
\hline \multirow[t]{3}{*}{3.2 - Understanding Process Requirements } & Scaling of Demonstration Tests \\
\hline & Modeling of Non-Newtonian Fluids \\
\hline & Process Performance with Polydisperse Solids \\
\hline \multirow[t]{5}{*}{$\begin{array}{l}3.3 \text { - Conditioning of Waste in the Tank } \\
\text { Farm or within WTP }\end{array}$} & $\begin{array}{l}\text { Size Reduction or Separation Techniques to Reduce or } \\
\text { Remove Large Particles }\end{array}$ \\
\hline & Enhanced Mixing Systems for Staging Feed \\
\hline & Washing or Pretreatment of HLW Sludge in the Tank Farm \\
\hline & Al Dissolution in the Tank Farm and Pretreatment Facility \\
\hline & Waste Feed Rheology Control \\
\hline \multirow[t]{3}{*}{$\begin{array}{l}\text { 4.1 - Representative Sampling of the Feed } \\
\text { Staging Tank and Process Vessels }\end{array}$} & $\begin{array}{l}\text { Unknown Sample Size for Waste Feed Qualification } \\
\text { Program }\end{array}$ \\
\hline & $\begin{array}{l}\text { Representative Sampling for Waste Feed Qualification } \\
\text { Program }\end{array}$ \\
\hline & $\begin{array}{l}\text { Isolok }{ }^{(B)} \text { Sampling System for Obtaining the Waste Feed } \\
\text { Qualification and Vessel Samples }\end{array}$ \\
\hline \multirow{3}{*}{$\begin{array}{l}4.2-\text { Waste Acceptance } \quad \text { Criteria/DQO } \\
\text { Analyses of Staged Feed }\end{array}$} & Extensive Analytical Requirements \\
\hline & Analytical Gaps and Improvements \\
\hline & Hydrogen Generation Rate Measurement \\
\hline \multirow{2}{*}{$\begin{array}{l}4.3 \text { - Process Qualification Program with } \\
\text { Waste Feed Qualification Sample }\end{array}$} & Pretreatment Process Demonstration \\
\hline & $\begin{array}{l}\text { Elimination of Glass Analyses Post Glass Former Addition } \\
\text { in the Waste Feed Qualification Process }\end{array}$ \\
\hline $\begin{array}{l}5.1 \text { - Use of VSL-HLP-0027/0028 for HLW } \\
\text { Product Qualification }\end{array}$ & $\begin{array}{l}\text { Develop, Demonstrate, and Implement Strategy to } \\
\text { Demonstrate Homogenous Mixing }\end{array}$ \\
\hline $\begin{array}{l}5.2 \text { - Basis for Number of Samples for } \\
\text { Analyses }\end{array}$ & $\begin{array}{l}\text { Review the Basis for Number of Samples and Recommend } \\
\text { Changes as Necessary }\end{array}$ \\
\hline \multirow[t]{2}{*}{$\begin{array}{l}5.3 \text { - Expansion of the Glass Composition } \\
\text { Envelope }\end{array}$} & $\begin{array}{l}\text { Broaden the Existing Glass Models to Cover Full Range of } \\
\text { Anticipated WTP Wastes }\end{array}$ \\
\hline & $\begin{array}{l}\text { Develop Glass Models for Specific Compositional Areas by } \\
\text { Waste Type }\end{array}$ \\
\hline \multirow{6}{*}{$\begin{array}{l}5.4 \text { - Potential Change in Repository } \\
\text { Requirements and Compliance Programs }\end{array}$} & Review Existing Requirements \\
\hline & Radioactive Qualification Demonstrations \\
\hline & Change in HLW Glass Canister Thickness \\
\hline & RW-0333P Quality Assurance Requirements \\
\hline & Required Analyte Reporting \\
\hline & Reducing Conservatism in HLW Wasteform Compliance \\
\hline \multirow[t]{3}{*}{6.0 - Simulant Selection and Development } & $\begin{array}{l}\text { Determine Bounding Chemical Compositions and Physical } \\
\text { Properties }\end{array}$ \\
\hline & Determine Properties to be Bounded by the Simulant \\
\hline & Develop Simulant Preparation Techniques \\
\hline
\end{tabular}




\section{TABLE OF CONTENTS}

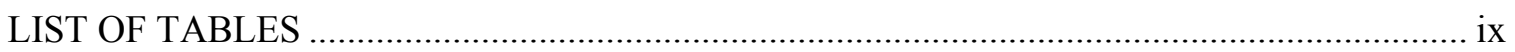

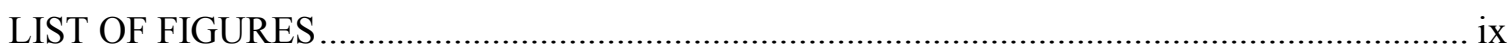

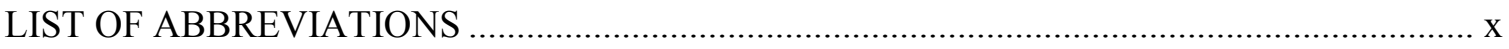

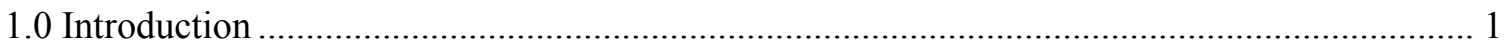

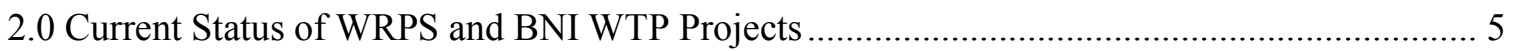

2.1 Feed Criteria Development Program and Status.............................................................. 5

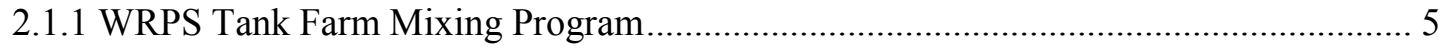

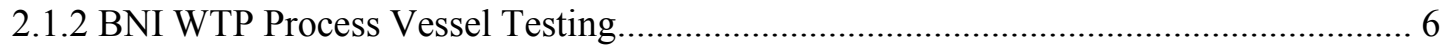

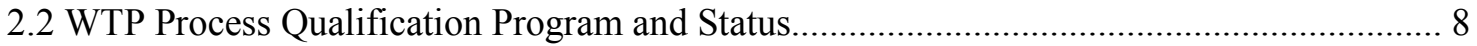

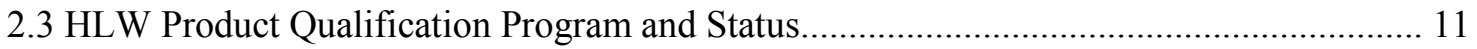

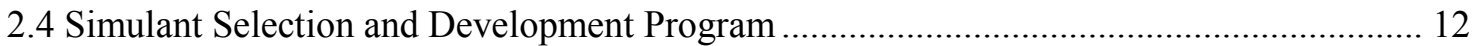

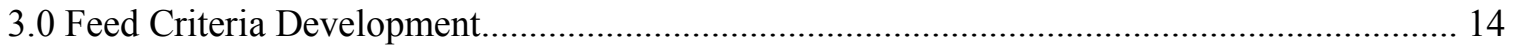

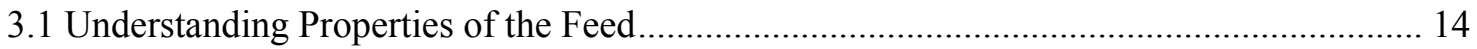

3.1.1 Parameters Controlling Waste Feed Rheology ....................................................... 15

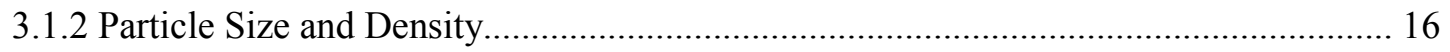

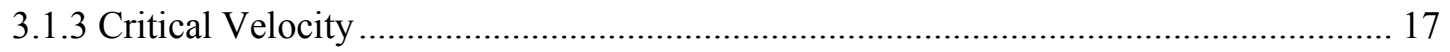

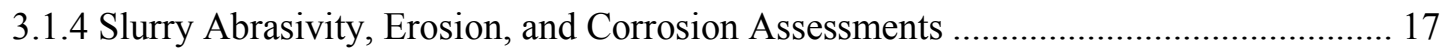

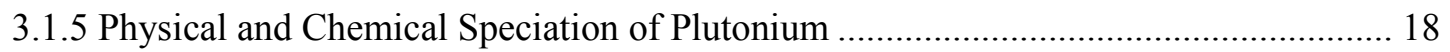

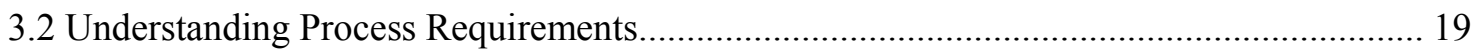

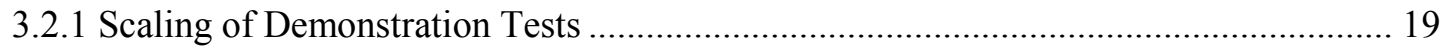

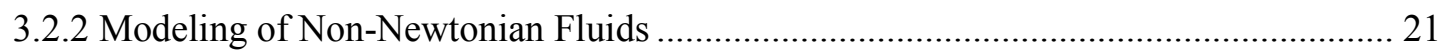

3.2.3 Process Performance with Polydisperse Solids........................................................... 22

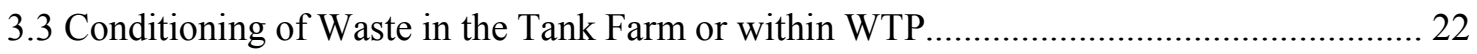

3.3.1 Size Reduction or Separation Techniques to Reduce or Remove Large Particles ........ 22

3.3.2 Enhanced Mixing Systems for Staging Feed ............................................................ 23

3.3.3 Washing or Pretreatment of HLW Sludge in the Tank Farm.................................... 23

3.3.4 Al Dissolution in the Tank Farm and Pretreatment Facility ........................................ 24

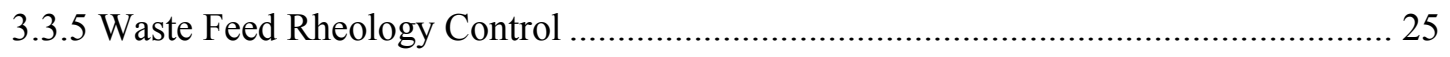

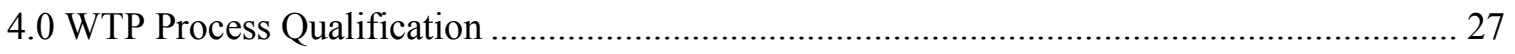

4.1 Representative Sampling of the Feed Staging Tank and Process Vessels ......................... 27

4.1.1 Unknown Sample Size for Waste Feed Qualification Program .................................. 27 
SRNL-STI-2012-00776

PNNL-22116

Revision 0

4.1.2 Representative Sampling for Waste Feed Qualification Program

28

4.1.3 Isolok ${ }^{\circledR}$ Sampling System for Obtaining the Waste Feed Qualification and Vessel

Samples 28

4.2 Waste Acceptance Criteria/DQO Analyses of Staged Feed 29

4.2.1 Extensive Analytical Requirements 29

4.2.2 Analytical Gaps and Improvements 30

4.2.3 Hydrogen Generation Rate Measurement ...................................................................... 31

4.3 Process Qualification Program with Waste Feed Qualification Sample.............................. 32

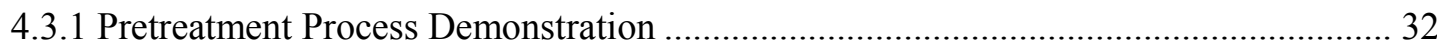

4.3.2 Elimination of Glass Analyses Post Glass Former Addition in the Waste Feed

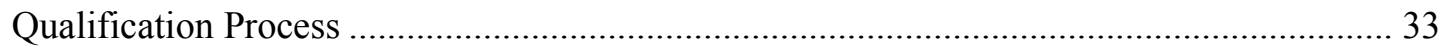

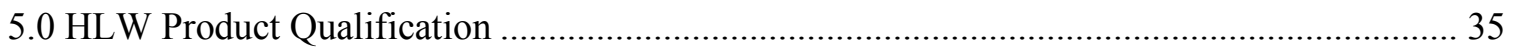

5.1 Use of VSL-HLP-0027/0028 for HLW Product Qualification............................................ 35

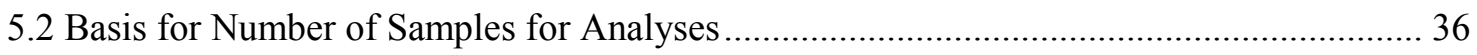

5.3 Expansion of the Glass Composition Envelope ............................................................. 37

5.4 Potential Change in Repository Requirements and Compliance Programs ........................ 38

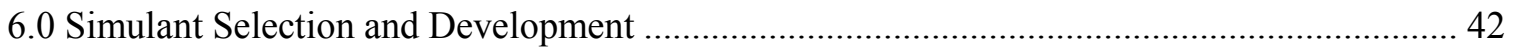

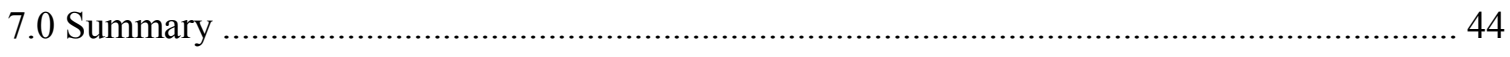

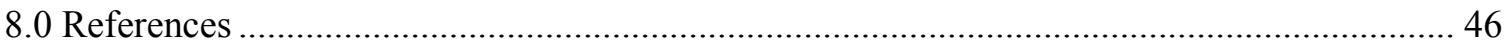


SRNL-STI-2012-00776

PNNL-22116

Revision 0

\section{LIST OF TABLES}

Table 3-1. Technology Gaps or Improvement Opportunities for Feed Criteria Development..... 14

Table 4-1. Technology Gaps or Improvement Opportunities for Feed Criteria Development..... 27

Table 5-1. Technology Gaps or Improvement Opportunities for Feed Criteria Development..... 35

\section{LIST OF FIGURES}

Figure 2-1. WTP Waste Acceptance, Qualification, and Process Control................................. 10

Figure 3-1. Example of Impact of Rheological Modifier........................................................... 26 


\section{LIST OF ABBREVIATIONS}

\begin{tabular}{|c|c|}
\hline BNI & Bechtel National, Inc. \\
\hline CFD & Computational Fluid Dynamics \\
\hline CUF & Cells Unit Filter \\
\hline DFs & Decontamination Factors \\
\hline DNFSB & Defense Nuclear Facility Safety Board \\
\hline DOE & Department of Energy \\
\hline DQO & Data Quality Objective \\
\hline DST & Double Shell Tanks \\
\hline DWPF & Defense Waste Processing Facility \\
\hline EA & Environmental Assessment \\
\hline EFRT & External Flowsheet Review Team \\
\hline EGCR & Experimental Glass Composition Region \\
\hline EM & Environmental Management \\
\hline FEP & Waste Feed Evaporation Process \\
\hline GPCP & Glass Product Control Program \\
\hline HGR & Hydrogen Generation Rate \\
\hline HLW & High Level Waste \\
\hline $\mathrm{ICD}$ & Interface Control Document \\
\hline IICD & Integrated Interface Control Document \\
\hline ISARD & Integrated Sampling and Analysis Requirements Document \\
\hline LA-ICP & Laser Ablation - Inductively Coupled Plasma \\
\hline LAW & Low Activity Waste \\
\hline LOAM & Low Order Accumulation Model \\
\hline LSIT & Large Scale Integrated Testing \\
\hline MFPV & Melter Feed Preparation Vessel \\
\hline MFT & Melter Feed Tank \\
\hline MFV & Melter Feed Vessel \\
\hline MOA & Memorandum of Agreement \\
\hline MTHM & metric tons of heavy metal \\
\hline MST & monosodium titanate \\
\hline ORP & Office of River Protection \\
\hline PCCS & Product Composition Control System \\
\hline
\end{tabular}


PCT Product Consistency Test

PJM Pulse Jet Mixer

PNNL Pacific Northwest National Laboratory

PSDD Particle Size and Density Distribution

QGCR Qualified Glass Composition Region

RCRA Resource Conservation and Recovery Act

RPP River Protection Project

SCIX Small Column Ion Exchange

SEM Scanning Electron Microscopy

SME Slurry Mix Evaporator

SNF Spent Nuclear Fuel

SRAT Sludge Receipt and Adjustment Tank

SRNL Savannah River National Laboratory

SRS Savannah River Site

TCLP Toxicity Characteristic Leaching Procedure

TLP Treated LAW Evaporation Process

TOC Tank Farm Operations Contractor

UF Ultrafiltration

UPE Ultrasonic PulseEcho

$\mathrm{V} \& \mathrm{~V} \quad$ Verification and Validation

WAC Waste Acceptance Criteria

WAPS Waste Acceptance Product Specification

WFA\&PQ Waste Feed Acceptance and Product Qualification

WFD Waste Feed Delivery

WRPS Washington River Protection Solutions

WTP Hanford Tank Waste Treatment and Immobilization Plant

WVDP West Valley Demonstration Project

XAS X-ray absorption spectroscopy

XRD X-ray Diffraction 
SRNL-STI-2012-00776

PNNL-22116

Revision 0

\subsection{Introduction}

The U. S. Department of Energy (DOE) - Office of Environmental Management (EM) has tasked the Savannah River National Laboratory (SRNL) and the Pacific Northwest National Laboratory (PNNL) to jointly coordinate the engagement of the broader national laboratory community to bring the scientific and technological rigor needed to evaluate/prioritize alternatives, define/execute technology development opportunities, and inform decisions that will reduce technical and programmatic risks. SRNL and PNNL have a strong knowledge of the EM mission needs and a long history of working with EM, contractors, other national laboratories, universities, and regulators to develop and deploy successful alternative approaches to many of EM's most challenging technical issues. Through a series of meetings amongst the national laboratories, site field offices and site contractors, four initiative areas were identified as being of most promise in terms of risk reduction as well as cost and schedule benefit. The initiative areas, focused on Hanford Tank Waste Management, were subsequently prioritized based on DOE - Office of River Protection (ORP) feedback and the Low Temperature Waste Forms with Technetium Removal/Disposal and the Waste Feed Acceptance and Product Qualification initiatives were selected for further follow-up. It was agreed that these initiatives would be started with FY12 funding. This document addresses the activities of the Waste Feed Acceptance and Product Qualification (WFA\&PQ) team.

The goal of the WFA\&PQ initiative is to assess the existing Tank Farm and WTP waste acceptance criteria and product qualification requirements and strategies to determine if any risk reduction or cost and schedule benefits can be obtained through additional national laboratory engagement. Based on the initial assessment, streamlining of the waste feed acceptance and High Level Waste (HLW) product qualification program appears feasible in some areas if a stronger technical basis can be provided. To accomplish this goal, SRNL and PNNL reviewed the existing Washington River Protection Solutions (WRPS) Tank Farm feed preparation tasks and acceptance criteria and the WTP Pretreatment Facility waste acceptance criteria, WTP qualification program, and HLW glass product qualification program. The programs were reviewed for potential technology gaps or improvement opportunities against known results from Hanford program testing and existing programs in place at the Savannah River Site (SRS) and lessons learned from the development and implementation of those programs. Consideration was also given to the potential Waste Acceptance Product Specification (WAPS) changes given the broader range of HLW disposal options being considered. This review identified three broad technical areas with specific technical gaps and approaches identified and a common challenge for all three areas. The three areas were 1) Feed Criteria Development, 2) WTP Process Qualification, and 3) HLW Product Qualification. Simulant Development was a common challenge and need for all of the technical areas.

For the Feed Criteria Development technical area, the focus will be on understanding the properties of the feed and the process requirements to underpin mixing, transfer, and acceptance in the Tank Farm and the WTP. For the WFA\&PQ initiative, the criteria for these process steps were assessed for potential gaps or improvements since realignment of the waste criteria has the potential to support resolution of technical issues associated with the design of WTP and asstored waste properties. Included in this gap analysis was the recently issued One System Gap Analysis ${ }^{1}$. Conditioning of the feed in the Tank Farm was also considered due to the potential benefit to the overall WTP flowsheet. 
The WTP Process Qualification technical area considered the various aspects of the waste feed qualification process for the WTP Pretreatment Facility. Qualification will include analyses of a suite of analytes, property testing, and demonstration of the WTP flowsheet for each campaign. The identified approaches for waste treatment will consider the impacts on other downstream processes such as vitrification and generation of secondary wastes.

The final technical area, HLW Product Qualification, focused on those efforts required to qualify the HLW waste form. The assessment started with mixing in the VSL-HLP-0027/28 vessels, went through sampling in the HLW Vitrification Facility and encompassed the models used to predict the performance of the waste form, the qualification program for the waste form, and the potential adjustments in disposal criteria and compliance that may be possible with a broader range of disposal options being considered. Some of these changes are more regulatory in nature but have the potential for significant savings over the mission life of the plant because they are performed with every campaign batch or melter feed batch to be processed. While the Low Activity Waste (LAW) waste form qualification and compliance program were not specifically considered in this initial assessment, pertinent changes from the HLW Product Qualification assessment will be considered for applicability to the LAW program.

In Section 2.0, the current status of each of these technical areas as understood by the team in November 2012 is provided. A subsection is also dedicated to the protocol for selecting and developing simulants for testing, which is a common need for all of the technical areas. Sections 3.0 through 6.0 provide the assessment of each of these areas broken down by the technology gaps, recommended approaches to close the gaps, and the significance and interfaces outlined for the gaps. However, before discussing the specific details of the Hanford processes and programs, a brief description of the SRS qualification process for the Tank Farm and the Defense Waste Processing Facility (DWPF) is provided for context given the common technical issues.

At SRS, the waste acceptance and compliance strategy for producing a HLW waste form is based on the operating philosophy that the best way to ensure acceptable glass is to control the feed composition. The control starts in the Tank Farm and relies upon homogeneous mixing, representative sampling, and qualification of the sludge batch before transfer to the DWPF. The fact that the sludge composition remains constant over the life of each Tank Farm sludge batch allows the DWPF Glass Product Control Program (GPCP) ${ }^{2}$ to be successful. In the DWPF, the homogeneous composition is maintained during each process step and compositional verification is performed as part of the control program. Prediction of the projected glass properties is performed for each melter feed batch using a set of correlations in the Product Composition Control System $(\mathrm{PCCS})^{3,4}$, which ensure durable glass is produced within the range of melter operating parameters.

To meet the chemical and radionuclide reporting requirements of the Waste Acceptance Product Specifications for Vitrified High Level-Waste Forms ${ }^{5}$ (DOE/EM-0093), samples from each Tank Farm sludge batch are analyzed to identify the elements that must be reported, which includes those present in the glass at $>0.5 \mathrm{wt} \%$. Before DWPF initiated operations, the representativeness of individual Tank Farm samples could not be completely demonstrated. Sampling and characterization experience indicated that analytical results for samples from a single tank were within $30 \%$ for the major elements. This variation potentially bound the mixing, sampling, and analytical uncertainty. ${ }^{2}$ Therefore, this conservative value was selected as input in the DWPF glass property models for DWPF reporting of all major species. Based on sludge analyses performed to date for DWPF, this number appears conservative when the tank contents have been 
well mixed and the solids are easily suspended with slow settling behavior. The ability to homogenize the tank contents and representatively sample was demonstrated by pulling multiple samples at different heights from sludge preparation tanks (i.e., Tank 40 or Tank 51 for DWPF). When DWPF started up, the requirement was mixing with 4 pumps for $>36$ hours but this has since been reduced to $\sim 8$ hours based on the supporting data from DWPF sludge batch qualification. The mixing pumps and configuration were selected for the range of rheological properties anticipated in the HLW and remaining within these bounds ensures homogeneous mixing and acceptable transfers to the DWPF.

During processing of the sludge batches in the DWPF, six samples are pulled for analysis and a minimum of four sets of results are reported from each process batch in the Sludge Receipt and Adjustment Tank (SRAT) and the Slurry Mix Evaporator (SME). The SRAT analyses are for process control, whereas the SME analyses are used to verify the glass product acceptance and melter process control limits using PCCS. The elemental results from the SME are also used for compliance reporting purposes. The glass property models in PCCS were developed before startup of the DWPF and contain both processing and product quality models for the glass composition. They were developed over the anticipated range of DWPF processing and underwent verification during DWPF qualification runs. The applicability of the durability models is confirmed with each sludge batch in a variability study performed during waste qualification. Some of the models in PCCS have been updated since the start of radioactive operations based on new data and glass theories, which have reduced the conservatism in DWPF operations.

The SME chemical composition analyses is a "Hold Point" in the facility and allows for any rework required (addition of either waste or frit) to ensure the acceptability of the glass prior to transferring feed to the melter. The SME product results are used by the DWPF to calculate the chemical composition of the glass, which is reported in the Production Records for that particular batch for the canistered waste form. Typically, a DWPF sludge batch (macro-batch) can range in volume from 250,000 to $1,000,000$ gallons so many SME batches ( 4500 gallons) can be processed as part of the sludge batch. For reporting, standard deviations for the sludge batch are appropriately calculated based on the entire set of analyses performed for the SME process batches. The reported composition for the sludge batch is subject to the following sources of error: feed non-uniformity, sampling variability, variability due to the analytical system, error in calculation of sludge batch composition, and DWPF SRAT/SME process variability. All of these errors are accounted for in the reporting and sufficient margin is included in the DWPF process and product control models (i.e., PCCS) to allow an acceptable product to be produced with some processing flexibility.

The SME, Melter Feed Tank (MFT), and melter are each expected to act as well-stirred vessels for normal operating conditions. The DWPF GPCP was developed to ensure acceptable glass by controlling the feed composition at the last feed preparation vessel (i.e., the SME), ensuring a representative sample is taken, analytical control of samples is demonstrated, and documented evidence is provided that control is achieved. ${ }^{2}$ This program was validated on a small-scale with simulants and radioactive material and on an engineering scale with simulants before DWPF start-up and then final validation occurred as part of the DWPF Startup Test Program. The program has been designed to be robust in order to handle changes, which have occurred in the 17 years of radioactive operations. 
Both the SME and the MFT have been designed to ensure that no segregation of material will occur that will affect glass product quality. If the process batch is not uniform, then samples of material taken from the SME vessel or the feed loop for the MFT are unlikely to be representative of the process batch. Thus the uniformity of the feed slurries must be controlled. Each tank is mixed by an agitator that has been designed to thoroughly homogenize the contents of the vessels. Based on testing performed at full-scale before start-up and process experience, the feed is expected to be uniform. The design of the vessels and agitators is based on the ability to homogenize non-Newtonian fluids representing a wide range of rheological properties (yield stress of 2.5 to 25 pascals, and a consistency of 0.01 to 0.06 pascal-seconds). Before the DWPF design was finalized and the facility started up, physical property measurements were performed on actual HLW samples to guide the equipment design and limits of operation. The rheological properties continue to be characterized for each sludge batch being processed in the Tank Farm and the DWPF to ensure that the slurries are within the design envelope of the process vessels and can be transferred. If they are not, the typical remedy has been either to dilute slurries that are too viscous or concentrate slurries that are too fluid. In the DWPF, adjustment of the acidification process can also be performed to manipulate the yield stress of the melter feed. 
SRNL-STI-2012-00776

PNNL-22116

Revision 0

\subsection{Current Status of WRPS and BNI WTP Projects}

Section 2 addresses the status of the contractor programs associated with the WFA\&PQ initiative. The section is divided into the three technical areas, which are further subdivided based on the different program areas. A fourth subsection discusses simulant development protocol, which is a common need for all of the technical areas. The status is based on the laboratories understanding of the programs as of November 2012.

\subsection{Feed Criteria Development Program and Status}

\subsubsection{WRPS Tank Farm Mixing Program}

The WTP is being designed and built to process and vitrify highly radioactive and mixed hazardous wastes stored in 177 underground HLW tanks at the Hanford Site. The waste is comprised of highly radioactive solids and liquid fractions in the form of sludge, salt cake, and supernatant liquid. Retrieval and transfer of the HLW to WTP is the responsibility of the Tank Farm Operations Contractor (TOC). The TOC responsibilities include staging the waste feed for transfer and providing a representative tank sample to WTP for waste qualification per the waste acceptance criteria $^{6}$. The ORP has defined the interface between the two prime River Protection Project (RPP) contractors, Bechtel National, Inc. (BNI) and WRPS, in a series of interface control documents (ICDs). The primary waste interface document is 24590-WTP-ICD-MG-01-019, "ICD-19-Interface Control Document for Waste Feed"?

The ability of the TOC to effectively mix, sample, certify, and deliver consistent batches of HLW feed from the Hanford Double Shell Tanks (DST) to the WTP has been recognized as a significant mission risk with potential to impact mission length and the quantity of HLW glass produced. Section 2.3 of ICD-19 states that the TOC baseline sampling plans and capabilities are not currently compatible with WTP sample and analysis requirements as described in Integrated Sampling and Analysis Requirements Document (ISARD) ${ }^{8}$, the Initial Data Quality Objectives for WTP Feed Acceptance Criteria ${ }^{6}$, and the Regulatory Data Quality Optimization Report ${ }^{9}$.

To ensure the Tank Farms and WTP mixing and sampling systems are integrated and compatible (i.e., execution of the One System approach) and the uncertainties identified by testing to date are addressed, the Waste Feed Delivery (WFD) Mixing and Sampling Program was expanded to include the following:

- Define DST mixing, sampling, and transfer system limits of performance with respect to the ability to transfer waste to the WTP with varying physical properties, solid particulates sizes and densities, and under various modes of operation (i.e., defining the expected range of particle size and density and consideration of data uncertainty).

- Define propensity of solid particulates to build up, and the potential for concentration of fissile material over time in DSTs during the multiple fill, mix, and transfer operations expected to occur over the life of the mission.

- Define ability of DST sampling system to collect representative slurry samples and in-line critical velocity measurements from a fully mixed waste feed staging tank.

- Develop sufficient data and methodology to predict confidently full-scale DST mixing, sampling, and transfer system performance; such that a gap analysis against WTP feed receipt system performance can be adequately completed. 
SRNL-STI-2012-00776

PNNL-22116

Revision 0

The WTP dynamic processing analysis and batch processing planning currently assumes each staged feed tank is mixed and delivered in consistent feed delivery batches of up to 145,000 gallons of HLW or LAW feed. ${ }^{7}$ Work is ongoing by the TOC to determine if consistent batches can be transferred from the Tank Farm to the WTP. ${ }^{10}$ Consistent, as used here is intended to mean that the first 145,000 gallon batch has the same solids chemical composition and physical attributes (e.g., mass loading) as the last 145,000 gallon batch from the waste feed staging tank. Small scale testing completed to date, as documented in RPP-50557 $7^{11}$, concluded that the first feed tank (241-AY-102) can likely be adequately mixed and sampled using DST mixing systems, but that additional questions related to data uncertainty, optimizing system performance, applicability to all feed tanks, and understanding emerging WTP solids handling risks still need to be addressed. The most recent testing on solids accumulation between transfers was documented in SRNL-STI-2012-00508 ${ }^{12}$.

The TOC is considering using the Ultrasonic PulseEcho (UPE) Technology developed by PNNL for deployment as part of the Hanford Waste Feed Flow Loop. This technology holds great promise to determine that the critical pipeline transfer velocity of the waste feed meets the HLW Feed Acceptance Criteria for this parameter. Extensive testing has been conducted with WRPS to prove the UPE technology, and deposition velocities determined with the UPE for a suite of simulants representing Hanford waste characteristics are within $0.3 \mathrm{ft} / \mathrm{s}$ of the visually determined reference (e.g. PNNL-22029) ${ }^{13}$. The degree of radiation hardening required and therefore the level of effort to field deploy the UPE system must be determined from the TOC prescribed contact exposure on the Hanford Waste Feed Flow Loop.

\subsubsection{BNI WTP Process Vessel Testing}

WTP performed testing in 2000-2004 to assess Pulse Jet Mixer (PJM) mixing of VSL-HLP-0027 and VSL-HLP-0028. ${ }^{14,15,16}$ Based on that testing, the vessels designs were validated against the assumptions at that time. In 2006, the External Flowsheet Review Team (EFRT) reviewed the WTP design and identified inadequate mixing system design as Major Issue 3 (M3) ${ }^{17}$. Following this review, WTP conducted testing, engineering calculations, engineering analysis, and Low Order Accumulation Model (LOAM) calculations to assess the adequacy of the PJM mixing in VSL-HLP-0027, VSL-HLP-0028, and other WTP vessels. ${ }^{14,18}$ The M3 issue was closed in 2010, with a number of post-closure recommendations. ${ }^{19}$

Following closure of M3, a review by the Defense Nuclear Facility Safety Board (DNFSB) resulted in recommendations for additional assessments of vessel mixing, and in response DOE prepared an implementation plan which directed WTP to conduct large scale integrated testing of selected WTP pulse jet mixed vessels that "address uncertainties and increase confidence in the projected, full-scale mixing performance and operations". Additionally, the testing would provide validation information necessary to complete system designs. These Large Scale Integrated Tests (LSIT) were originally to be conducted in $4 \mathrm{ft} ., 8 \mathrm{ft}$., and $14 \mathrm{ft}$. vessels, and included CFD V\&V, Performance and Scaling, PJM Control, and Limits of Performance test campaigns. ${ }^{20}$ WTP has recently received direction from the Secretary of Energy to change the objectives and scope of the testing. DOE and WTP are currently working to redefine the objectives and scope of the LSIT.

As it currently stands, the LSIT Program includes the following tasks: Properties, Simulants, Scaling, and Testing. 
The objectives of the Properties task are to assess physical and chemical properties important to the testing and development of mixing scaling relationships, and identify the governing properties and associated ranges for LSIT to achieve the test objectives. This task has been completed. ${ }^{21}$

The Simulant task includes developing a simulant basis and conducting simulant qualification. The simulant basis task will identify the specific simulant characteristics and properties that are needed to address specified test objectives. The task will also determine the complexity of simulant needed to meet the test objectives (e.g., physical versus chemical simulants), and document a recipe for each of the simulants recommended. The simulant qualification task will involve preparing small batches of simulant and confirming that the batches have the targeted properties.

The purpose of the Scaling task is to provide a technical basis for the operating conditions and geometric configurations of small scale test vessels in order to determine the performance and uncertainty in mixing WTP vessels with pulse jet mixers. The Scaling task provides a technical basis for extrapolating mixing performance test data from small scale (i.e., $4 \mathrm{ft}$., $8 \mathrm{ft}$., and $14 \mathrm{ft}$. diameter) to larger/full scale (14 - $37 \mathrm{ft}$. diameter).

WTP Engineering conducted a workshop that identified general test objectives that have been incorporated in responses to the Defense Nuclear Facility Safety Board (DNFSB) recommendation 2010-2 22 , the latest revision of the Integrated Pulse Jet Design and Control Strategy $^{23}$, and the latest draft LSIT request for technology development. The LSIT objectives have been grouped into the following topics:

- Performance Testing

- Scaling Testing *

- Heel Management

- Design and Safety Margin

- Computational Fluid Dynamics (CFD) Comparison *

- Limits of Design Testing

- Pulse Jet Mixer (PJM) Controllability

- Bubbler Accuracy

- Sampling Capability

- Transfer and Pump-out

- Prototypic Integrated Operation

- FLUMP Validation *

- PJM Restart

- Sparger Operation

(* these programs are subject to potential modification related to feedback from the S1 Black Cell Team)

The WTP LSIT program plans included conducting the following sets of tests: CFD verification and validation $(\mathrm{V} \& \mathrm{~V})$, performance and scaling, pulsed jet mixer control, and limits of performance. The CFD V\&V testing goal is to collect data for comparison with CFD calculations to determine the uncertainty in the calculations that are used for WTP design verification. The performance and scaling testing objective is to determine whether the pulsed jet mixers produce adequate mixing in process vessels to meet the WTP mixing requirements. PJM controllability involves testing to confirm that an actual process control system for the PJM air-vacuum pulses will function correctly at large scale in representative systems. The limits of performance testing 
will vary the simulant properties outside of the WTP design to determine the properties at which the pulsed jet mixers cannot meet the WTP mixing requirements (i.e., the system fails). ${ }^{\text {i }}$

\subsection{WTP Process Qualification Program and Status}

The waste feed qualification program is being developed to protect the WTP design, safety basis, and technical basis by assuring acceptance requirements can be met before the transfer of waste from the TOC to WTP. The WTP Project is developing the waste feed qualification program. ${ }^{24}$ The results of waste feed qualification activities will be implemented using a batch processing methodology, and establish an acceptable range of operator-controllable parameters needed to treat the staged waste. A schematic of the WTP Waste Acceptance, Qualification, and Process Control strategy is provided in Figure 2-1.

In general, the waste feed qualification program involves testing and analysis to demonstrate compliance with waste acceptance criteria, determine waste processability, and demonstrate laboratory-scale unit operations. The testing and analysis are driven by data quality objectives (DQO) necessary to ensure meeting a) waste acceptance criteria for transfer of wastes from the tank farms to the WTP, b) waste processability including proper glass formulations, and c) design and nuclear safety requirements during processing within the WTP complex. ${ }^{6,7,89}$ The WTP has defined its program to meet these objectives and has engaged SRNL to assess, verify, validate, and support development of the waste feed qualification program. During Phase 1 of the waste feed qualification program development, test methods were identified by WTP to perform the physical, chemical, radiochemical, and organic analyses required to meet the waste acceptance criteria ${ }^{6}$. SRNL subject matter experts reviewed these test methods, and either provided concurrence, proposed an alternative method, or confirmed that a method gap existed. ${ }^{25}$ Method gaps for four waste feed acceptance parameters were identified: hydrogen generation rate (HGR), critical velocity, abrasivity, and ${ }^{231} \mathrm{~Pa}$ measurement. Some of these same gaps were identified in the One System Gap Analysis. ${ }^{1}$ The HGR and abrasivity gaps will be developed in Phase 2 of the program, which was initiated in FY12. The critical velocity gap is being addressed by the TOC and the ${ }^{231} \mathrm{~Pa}$ measurement capability is currently on hold.

Before each feed campaign is transferred to the WTP, laboratory-scale demonstrations of the WTP Pretreatment Facility processes and feed preparation for the LAW and HLW Vitrification Facility will be performed using methods and equipment developed ahead of time. Development of the laboratory scale apparatus needed to perform the unit operations demonstrations is also part of the Phase 2 waste feed qualification program development. The goal of the demonstration is to perform the WTP waste qualification for the following unit operations:

- WTP Prime Contract Specification 12 testing $^{26}$ : Predict the quantity of immobilized high-level waste product and immobilized low-activity waste product produced as a result of (1) solids washing; (2) caustic leaching and washing; and (3) either (1) or (2) combined with oxidative leaching and washing. A single set of parameters shall be selected for evaluation during the qualification sludge washing and leaching testing.

- Waste concentration: Perform boil-down evaluations to monitor changes in physical properties and observe any occurrence of foaming to ensure waste concentration within waste feed evaporation process (FEP) system and treated LAW evaporation process (TLP) system operational limits.

${ }^{\mathrm{i}}$ LSIT testing is being revised at the direction of the Secretary of Energy. 
SRNL-STI-2012-00776

PNNL-22116

Revision 0

- Sludge washing and leaching: Demonstrate caustic/oxidative leaching parameters selected during Specification 12 activities. ${ }^{26}$

- Cross-flow ultrafiltration: Evaluate ultrafilter performance using a cells unit filter (CUF) apparatus, evaluate rheology at selected intervals, obtain permeate necessary for Cs ion exchange testing, and obtain the slurry phase for HLW glass production. 


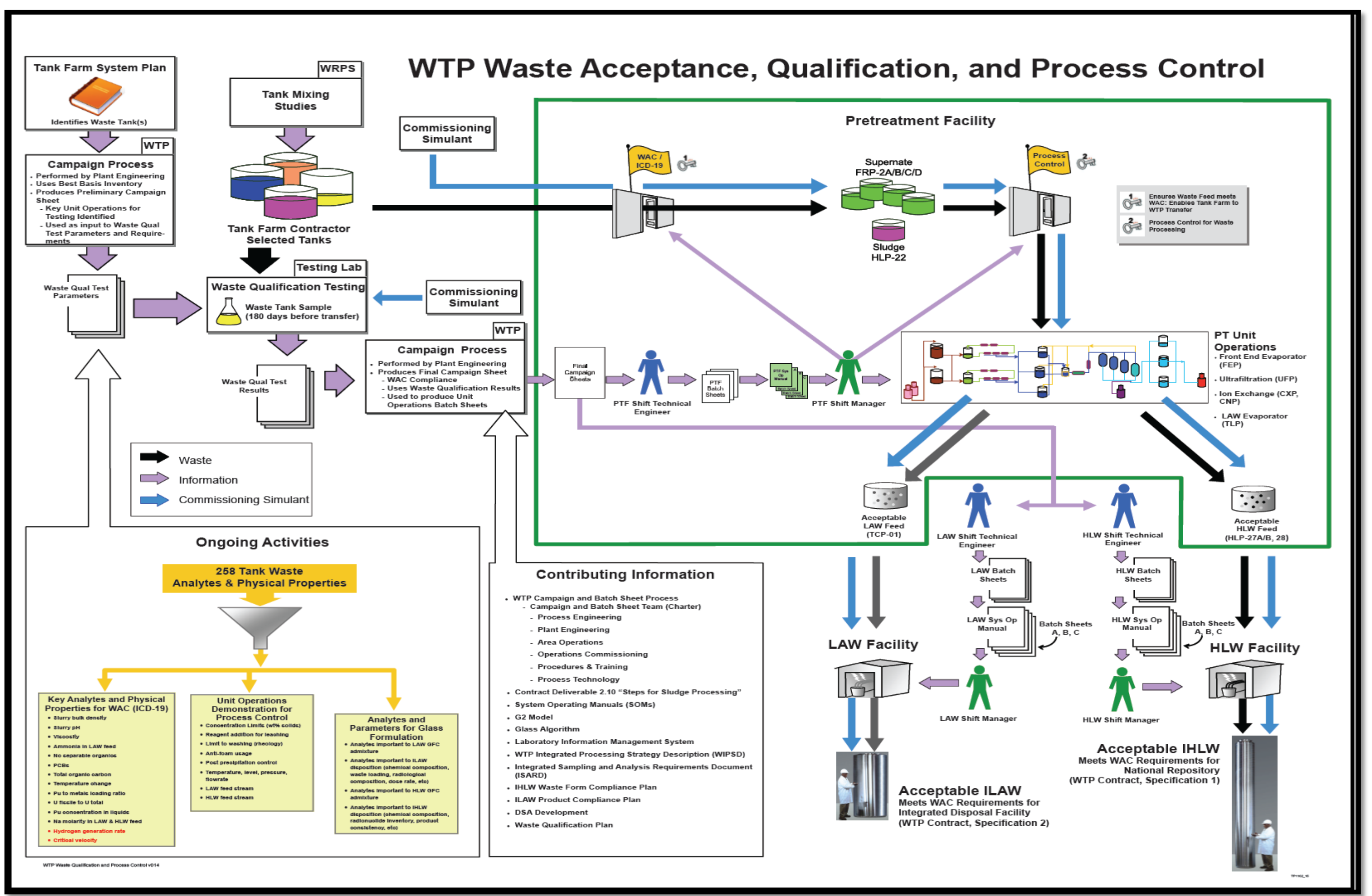

Figure 2-1. WTP Waste Acceptance, Qualification, and Process Control. 
SRNL-STI-2012-00776

PNNL-22116

Revision 0

- Ion exchange for ${ }^{137} \mathrm{Cs}$ removal: Obtain ion exchange effluent for LAW glass production, obtain ion exchange regeneration eluent for HLW glass production, and evaluate spent resin to obtain information related to the spent resin disposal path in the Pretreatment Facility.

- Glass formulation and analysis: Evaluate rheology of LAW and HLW combined with glass former chemicals, and fabricate LAW and HLW glasses for analytical characterization.

During the demonstration of the campaign-specific waste treatment strategy, unit-specific parameters are to be measured along with measurements of hydrogen generation rate, rheology, and visual observations for the presence of foaming.

Although the waste acceptance criteria have been developed through the process presented in the WAC DQO ${ }^{6}$ and ICD-19 - Interface Control Document for Waste Feed ${ }^{7}$, finalization of the documented safety analyses, additional data quality objectives work, and final design activities may result in change. Changes will be incorporated into the waste qualification program as appropriate.

\subsection{HLW Product Qualification Program and Status}

The HLW glass (waste form) to be produced by the WTP will be required to meet the DOE Waste Acceptance Product Specifications for Vitrified High Level Waste Forms ${ }^{5}$, the Waste Acceptance System Requirements Document (WASRD) ${ }^{27}$, the Integrated Interface Control Document (IICD) ${ }^{28}$, the Memorandum of Agreement (MOA) for Acceptance of Department of Energy Spent Nuclear Fuel and HLW ${ }^{29}$, and the WTP contract $^{30}$. The methodology WTP will use to demonstrate compliance with these specifications is outlined in the Waste Form Compliance $\operatorname{Plan}^{31}$ and the Waste Qualification Report ${ }^{32}$.

In summary, the HLW Vitrification Facility will receive concentrated feed in batches from the Pretreatment Facility in each of the two melter feed preparation vessels (MFPVs). The HLW slurry will be sampled (four samples) and analyzed for major chemical constituents. The glass formers will be determined based on the glass property - composition models prediction. Once the glass formers are added and a uniform mixture is obtained, the feed will be re-sampled (eight samples) and the melter feed composition will be confirmed before transferring the feed to the melter feed vessel (MFV) from which it is continuously fed into the melter. The molten HLW glass is poured into stainless steel canisters, which are inspected, measured for fill height, and glass samples are taken if necessary. The canister is then welded, decontaminated, and inspected to ensure compliance. The canister will then be transferred to interim storage in the canister storage building on the Hanford Site.

In order for the WTP to successfully comply with the specifications for making an acceptable glass, an experimental glass composition region (EGCR) that bounds the expected chemical and radiochemical compositions of the HLW product must be developed and confirmed. The WTP HLW qualification program will ensure that glasses produced from the range of feed delivered to the HLW Vitrification Facility will be bounded by a glass composition region that is within the qualified glass composition region (QGCR) - a composition region within the EGCR for which all the product requirements are met. The QGCR was developed based upon crucible-scale and melter-scale testing with simulants, and crucible-scale tests with actual wastes. The QGCR definition accounts for variation and uncertainties in batch compositions, transfer volumes, sampling, analytical results, model predictions, and melter decontamination factors (DFs) ${ }^{33}$. The 
composition results from waste feed qualification testing will be used to confirm that the staged waste feeds will be within the QGCR and will make acceptable glass through composition assessments before the waste batch is delivered to the WTP. During production, each Melter Feed Preparation Vessel (MFPV) batch will be analyzed, and the results will be used along with glass property-composition models to determine the appropriate glass forming chemicals for addition and to demonstrate that the glass meets property requirements. The results will be documented in the production records.

The reporting of the chemical and radionuclide composition will be based on analysis of samples from the MFPV. As described above, each batch transfer to the MFPV will be characterized to calculate the correct glass former additions to ensure the resulting glass will be within the QGCR and can be processed within the melter. After the glass former addition, re-sampling will occur to confirm the glass former addition, determine chemical and radionuclide composition for reporting, estimate Product Consistency Test (PCT) response (i.e., durability), and demonstrate delisting compliance (i.e., Toxicity Characteristic Leaching Procedure). Sampling and analyses of the melter feed in the MFPV will be performed in a manner as to produce insignificant composition biases and the random composition uncertainties will be reported and used in meeting property requirements with sufficient confidence. The predicted PCT responses will be below the Environmental Assessment (EA) glass values with 95\% confidence. Uncertainties accounted for in this confidence interval include: mixing and sampling of the melter feed in the MFPV, melter feed composition analyses, variation between batches being averaged to yield canistered glass composition, melter DFs, and prediction uncertainties. Toxicity Characteristic Leaching Procedure (TCLP) response and processing related property response predictions will be met with 90\% confidence per the Environmental Protection Agency requirements. The melter feed will not move forward until it has been shown to be compliant. Before the facility is started up, the relationship between the melter feed composition and the final glass composition will be demonstrated and the ability to homogeneously mix and accurately sample the MFPV will be confirmed. During cold commissioning of the facility, WTP will demonstrate that the composition of the MFPV can be used to report the waste form composition based on glass product samples. $^{31}$

In order to report the radionuclide composition during production, the MFPV batches from a given HLW blend vessel batch (VSL-HLP-0028) will be analyzed for a minimal list of radioactive constituents to evaluate compliance with HLW glass product specifications (all radionuclides at $\geq 0.05 \%$ of the total activity between years 2015 and 3115 ). One of the MFPV batches from the blend vessel batch will undergo a full set of analyses for the radionuclide constituents, which will be assigned to all MFPV batches from the same blend vessel batch. ${ }^{31}$

\subsection{Simulant Selection and Development Program}

The selection and development of a simulant for testing is a common need for all three technical areas. Development of a simulant protocol relies upon definition of the testing involved. Four types of non-radioactive simulants can be utilized to perform process testing for evaluation of the Hanford WTP processes. The first type of simulant is a physical simulant designed to mimic the physical properties of the fluids expected during processing. The second type is a "behavioral" simulant used to mimic processing behavior. The third type is a chemical simulant designed to mimic the chemistry of the process fluids. The fourth type of simulant is the prototypic simulant designed to match both the physical and chemical properties of the process fluids. Frequently, the prototypic simulants are prepared by mimicking the chemical processes that generated the waste. 
The physical simulant is the simplest and least expensive simulant to prepare and is typically nonhazardous. This simulant can be as simple as water with a rheological modifier (xanthan gum, laponite, kaolin, etc.) or can be a more complex mixture of salt laden supernate with various types of solids. As the name suggests, this simulant is limited to studies involving physical properties only (mixing, pumping, settling, etc.). A second type of simulant, the "behavioral" simulant is a special type of physical simulant that uses a surrogate material to mimic the processing behavior of the waste (e.g., filtration rates).

A chemical simulant is much more complex and expensive than the physical simulant and frequently contains the Resource Conservation and Recovery Act (RCRA) metals found in the waste as significant waste components other than radioactive species can be included when complex chemical reactions are occurring. Some radioactive species (e.g. cesium) have nonradioactive isotopes than can be utilized. A surrogate can be used in place of a radioactive component, but differences in the chemistry of surrogate and radioactive species need to be considered and incorporated in the testing. While the chemical reactions can be studied with these simulants, physical properties such as yield stress are frequently not representative of the actual waste. Chemical simulants are often used during melter studies both for SRS and Hanford programs.

The fourth simulant, the prototypic simulant, attempts to match the chemical and physical properties of the waste as closely as possible. This simulant is the most difficult to prepare as it is the most constrained. Certain process evaluations, such as foaming and rheological modification studies, require a prototypic simulant in order to be effective. The challenges of preparing a prototypic simulant for wastes containing solids frequently require compromise in some area which typically prevents the simulant from matching all characteristics of the actual waste. Prototypic simulants are used at SRS for sludge batch qualifications studies, mixing studies, and sampling studies up to full scale for the DWPF process. This type of simulant has been used for lab-scale process evaluations of the WTP processes. 
SRNL-STI-2012-00776

PNNL-22116

Revision 0

\subsection{Feed Criteria Development}

This section identifies the technology gaps and potential approaches that can be used to close those gaps for the Feed Criteria Development technical area. Section 3.1 addresses the properties of slurries within the waste treatment complex (tanks farms and WTP). Section 3.2 addresses process requirements for the Tank Farm and the WTP. Section 3.3 provides a listing of alternative technologies that could be implemented in the Tank Farm or WTP to mitigate some of the technical challenges in the Pretreatment Facility. The technology gaps or improvement opportunities addressed in sections 3.1 through 3.3 are summarized in Table 3-1.

Table 3-1. Technology Gaps or Improvement Opportunities for Feed Criteria Development

\begin{tabular}{|c|c|}
\hline Section & Technology Gap/Improvement Opportunity \\
\hline \multirow{5}{*}{$\begin{array}{l}\text { 3.1 - Understanding Properties of the } \\
\text { Feed }\end{array}$} & Parameters Controlling Waste Feed Rheology \\
\hline & Particle Size and Density \\
\hline & Critical Velocity \\
\hline & $\begin{array}{l}\text { Slurry Abrasivity, Erosion, and Corrosion } \\
\text { Assessments }\end{array}$ \\
\hline & Physical and Chemical Speciation of Plutonium \\
\hline \multirow{3}{*}{$\begin{array}{l}3.2 \text { - Understanding Process } \\
\text { Requirements }\end{array}$} & Scaling of Demonstration Tests \\
\hline & Modeling of Non-Newtonian Fluids \\
\hline & Process Performance with Polydisperse Solids \\
\hline \multirow[t]{5}{*}{$\begin{array}{l}3.3 \text { - Conditioning of Waste in the } \\
\text { Tank Farm or within WTP }\end{array}$} & $\begin{array}{l}\text { Size Reduction or Separation Techniques to } \\
\text { Reduce or Remove Large Particles }\end{array}$ \\
\hline & Enhanced Mixing Systems for Staging Feed \\
\hline & $\begin{array}{l}\text { Washing or Pretreatment of HLW Sludge in the } \\
\text { Tank Farm }\end{array}$ \\
\hline & $\begin{array}{l}\text { A1 Dissolution in the Tank Farm and Pretreatment } \\
\text { Facility }\end{array}$ \\
\hline & Waste Feed Rheology Control \\
\hline
\end{tabular}

\subsection{Understanding Properties of the Feed}

The extent of knowledge of the chemical, physical, and rheological properties of Hanford Site waste is a key component to the success of the design and operation of the WTP waste processing facilities. These properties are critical for facility designs and engineering calculations. Knowledge of the waste properties is also necessary for the development and fabrication of simulants that are used in testing.

The national laboratories reviewed models and correlations related to waste storage, mobilization, transport, and processing to identify the waste parameters important to quantifying the phenomena of storage, mobilization, transport, and processing. ${ }^{21,34}$

Solid particle characteristics as well as slurry rheology are significant parameters to understanding waste storage, mobilization, transport, and processing of slurries. A comprehensive review of the Hanford tank waste database ${ }^{34}$ has identified aspects of these parameters as specific gaps in the waste properties for which relatively little information is 
available, and also noted their inclusion for specific gaps in analytical methods as applied to actual waste samples.

The Properties that Matter $\operatorname{task}^{21}$ showed the most important properties for testing with Newtonian slurries are the Archimedes number distribution and the particle concentration. For some test objectives, the shear strength is important. In the testing to collect data for CFD V\&V and CFD comparison, the liquid density and liquid viscosity are important. In the high temperature testing, the liquid density and liquid viscosity are important. The Archimedes number distribution combines effects of particle size distribution, solid-liquid density difference, and kinematic viscosity.

The most important properties for testing with non-Newtonian slurries are the slurry yield stress, the slurry consistency, and the shear strength. The solid-liquid density difference and the particle size are also important. It is also important to match multiple properties within the same simulant to achieve behavior representative of the waste.

Other properties such as particle shape, concentration, surface charge, and size distribution breadth, as well as slurry cohesiveness and adhesiveness, liquid $\mathrm{pH}$ and ionic strength also influence the simulant properties either directly or through other physical properties such as yield stress.

This section describes technology gaps associated with physical and rheological properties of Hanford Site waste and thus WPT feed batches and process streams, specifically for solid particle characteristics and slurry rheology. Also, included are the approaches and tasks for closing the gaps. The gaps identified in this section are some of the same gaps identified in the One System Gap Analysis ${ }^{1}$.

\subsubsection{Parameters Controlling Waste Feed Rheology}

Technology Gap: To date, there is very limited correlation of the physicochemical parameters of the tank waste to the tank waste rheology. As a result, it is very difficult to predict the rheology of proposed batches of feed based on the information available today. As such, there exists a significant risk that feed batches could be prepared that do not meet either the Tank Farm or WTP rheology requirements without dilution.

Approach: This effort would involve a series of tests to evaluate the potential parameters that impact the rheology of HLW feeds. The primary parameters of interest would include mineral phase, crystallinity (that is tests using both crystalline and amorphous mineral phases where appropriate), particle size and the solvent phase. Additional parameters would be tested based on the outcome of the correlations from tank waste samples. Prior work has provided some preliminary insight into the impacts of particle sizes, particle shapes and some mineral forms.

The task would be divided into three phases.

Phase 1 - Mineral phase identification: An extensive characterization of the mineral phases present in Hanford Tank Waste is currently in progress in support of the WTP erosion program. This work would be leveraged to identify the mineral phases for potential testing. The existing characterization data would be analyzed to determine the most significant mineral phases present in tank waste. Subsequently, rheology measurements would be made with simulated streams containing the mineral phases of interest. In addition, additional tests would be performed with 
either amorphous or crystalline materials, as appropriate and with materials of varying particle sizes. This information would then be used to develop a more complete understanding of the parameters impact on rheology.

Phase 2 - Insoluble solids concentration and rheology: Subsequently, the mineral phases that exhibit the most extreme rheological behavior would be further investigated to determine the impact of the insoluble solids concentration on rheology of the materials. It should be noted that the impact of insoluble solids will vary depending upon other properties of the wastes.

Phase 3 - Rheology of processed and blended streams: The final step in the process would be to determine the impact of processing and of blending on the rheological properties. In particular, this work would evaluate the impact of leaching on rheology and the impact of blending various mineral phases. Laboratory studies with radioactive samples have shown that available models predict blended properties fairly well when the properties of the individual wastes are known. ${ }^{35}$ Therefore, an approach that could be taken is to measure the rheology of the individual wastes that will be blended and to use this information in determining a blend that will be acceptable before staging the waste in the feed tank.

The approach and tasks are planned with the intent of gaining better understanding of rheology to allow the Tank Farm contractor greater control of the rheology of future WTP feeds. While it is unlikely that this effort will allow direct prediction of the rheology of any given feed, information should be gained on the behavior of the waste types and on the impacts of processing. This information could then be used to avoid staging of feed batches which do not meet WTP waste feed acceptance criteria.

Significance/Interfaces: Understanding the rheology of the expected feeds will provide the TOC and WTP with information to plan their processing. This might include changing how slurries are blended or are processed in the facility such that rheological limits are not exceeded. The information gained in this task could be used before or after facility start-up and for Tank Farm or Pretreatment streams.

\subsubsection{Particle Size and Density}

Technology Gap: The density of solid particles, directly associated with particle size, is a key parameter to understanding many of the waste storage, retrieval, and treatment processes. The combination of solid particle size and density is described as a particle size and density distribution (PSDD).

How a particle of a certain size and density will behave during waste storage, retrieval, and treatment processes can be considered via models and correlations for those processes as previously described. For simulant evaluation and development for the TOC Waste Feed Delivery Mixing and Sampling Program tank performance testing, Wells et al. ${ }^{36}$ and Lee et al. ${ }^{37}$ considered a suite of metrics. The effect of a particle's size can be more or less significant than its density depending on the process being considered. Particle settling in the Stokes flow regime has a greater dependence on particle size, while particle mobilization, off-bottom suspension, and pipeline transport critical velocity are all shown to be more dependent on particle density than size.

Although there are numerous studies investigating the particle size of Hanford waste, there are a limited number of measurements available for a composite solids density, and this parameter has 
not been generally measured directly on samples. The density of individual solid particles is typically estimated based on the waste chemistry. The methods currently available to determine composite solids density include the use of gas pycnometers, a displacement method based on the use of dodecane, and calculating it as part of solid concentration analyses. These methods are limited in application to individual particles, and provide no information for particle size.

PSDDs for Hanford wastes are currently developed with separate analytical techniques for size and density. One coupled concept under development is a Particle Size and Velocity System. The method uses a settling column in which particulates settle through an appropriate fluid. Cameras obtain images of the settling particles with a sufficient magnification and frame rate to allow a determination of the settling rate. Particle size and shape information is also obtained. From these data, settling rate models can be used to determine the effective particle density for the sample conditions, and thus PSDDs would be determined.

Approach: This task would continue the development and validation of the Particle Size and Velocity System ${ }^{38}$ using simulants representative of Hanford waste with the goal of developing a laboratory technique that can be deployed to directly measure waste particle density coupled with size and shape. The eventual goal of this work is to deploy this technology on representative actual waste samples. Quantification of the significant parameter of particle density would be made, and the likelihood of large and or dense particles challenging to waste processing can thus be more accurately investigated.

Significance/Interfaces: The capabilities of the Tank Farm and WTP waste processing systems are limited in comparison to the Hanford waste properties. Slurry rheology, particle size, and density have an impact on these systems and need to be understood.

\subsubsection{Critical Velocity}

Technology Gap: The TOC is investigating methods for in-line critical velocity measurements as discussed in Section 2.1.1.

Approach: At the SRS, critical velocity is not measured for each sludge transfer. A bounding approach has been implemented instead that relies upon engineering calculations to determine the acceptable rheological properties for transferring the sludge. The calculations use the density, weight percent solids, and rheology of the material to be transferred in conjunction with the transfer velocity and required transfer distance to determine whether an acceptable transfer will be made using known slurry transport correlations. This same type of approach could be implemented for WTP and will be investigated for applicability.

Significance/Interfaces: Using this approach would allow the TOC to use data that is already being determined to support the transfer. This approach would apply to transfers from the Tank Farm to the Pretreatment, LAW Vitrification, or HLW Vitrification facilities.

\subsubsection{Slurry Abrasivity, Erosion, and Corrosion Assessments}

Technology Gap: Transfer lines, vessels, piping, and other facility components within the tank farm and the WTP will contain continuous flows of solids-liquid mixtures that may cause degradation or wear to the pipes and associated equipment particularly for a plant lifetime of 40 years. Wear occurs as the abrasive particles remove (or displace) material from the solid surface. Wear may also be accelerated by synergetic effect of corrosion. Slurry abrasion (wear) is a complex phenomenon and is influenced by a number of factors such as particle size, shape, 
mechanical properties of the particle (i.e., hardness and shear strength, fracture toughness) and wearing surface, the magnitude and direction of stress that is exerted by the particle, and the slurry rheology. The chemistry of the slurry may also affect the wear process. To ensure that the Hanford waste treatment system is in good working order over the design life, the rates of wear need to be quantified or understood. Once the wear rates are known, design requirements and maintenance schedules can be developed to assure continuous safe plant operation.

Approach: Abrasivity determination of the waste feed for the tank farm to WTP transfer was identified as a gap in the development of the WTP waste feed qualification program. ${ }^{25}$ WTP is currently funding the SRNL to develop a tool for measuring the abrasivity of the qualification sample for each campaign. This technique will determine the relative abrasivity of the slurry, which is related to the rate of mass loss from a standard material. The protocol will be developed as part of the Phase 2 effort for the WTP program. However, this technique will only address the relative abrasiveness of the waste feed and has not been correlated to the wear of the system components or materials. Therefore, concerns may still exist in other areas of the Tank Farm or WTP facility.

Preliminary evaluations of slurry wear or abrasivity were conducted for the WTP Project, but the flow loops to perform actual testing were not built and no testing was conducted to measure the wear rates. To close the gap, the scaled flow loops would be designed and constructed to represent full-scale systems in the WTP. It is recommended that the work be continued with WTP on erosion issues as follow-on to the evaluation documented in the "RPP-WTP Slurry Wear Evaluation: Slurry Abrasivity" 39 technical report.

Before start-up of the DWPF, coupon testing and large-scale system testing were performed to determine the potential areas of concern with respect to erosion and corrosion. Changes in the materials of construction and equipment designs were made to mitigate the problem areas. The identified areas of concern were then monitored during qualification runs with simulants in the DWPF and changes were made before radioactive operations commenced. In some cases, physical changes were not possible so monitoring and replacement programs were put in place. The national laboratories can develop a similar strategy for Hanford that can be implemented in the planned start-up or qualification testing for the Tank Farm and the WTP.

Significance/Interfaces: A lot of recent focus has been put on wear issues for the WTP Pretreatment Facility. Understanding the real properties of the waste and performing the necessary assessments to determine potential wear will be critical to meet design life for WTP and for mixing in and transfer from the Tank Farm.

\subsubsection{Physical and Chemical Speciation of Plutonium}

Technology Gap: In WTP's design basis, assumptions about plutonium form and particle size introduce significant adverse implications affecting the feed transfer and processing requirements. Most deleterious are the assumptions that relatively large $(100 \mu \mathrm{m})$, high density $(19 \mathrm{~g} / \mathrm{mL})$ plutonium oxide and/or plutonium metal particles exist. Under these assumptions, the ability to suspend and move particles via pumping may be clearly hampered, and the possibility of plutonium particles becoming segregated from the bulk waste becomes an issue, which is being addressed by the WTP Project in a revision to their Criticality Safety Evaluation Report. Although the form and size assumptions may be appropriate, there is currently insufficient sample characterization data to demonstrate their validity. If the form of the plutonium is such that the 
density is significantly lower and/or the plutonium particle size is smaller, the requirements for processing such particles become significantly more manageable.

Approach: Multiple analytical methods offer the potential for characterizing the physical and chemical characteristics of solid-phase plutonium. Scanning electron microscopy (SEM) and Xray diffraction (XRD) have been successfully utilized to identify plutonium particles associated with iron minerals in solid samples collected from SRS waste tank 18F. Specifically, these techniques provided a means of estimating the plutonium particle sizes and concentrations, and identifying the iron minerals on which the plutonium particles were found. Mineral characterization of plutonium is a possibility using XRD depending on the magnitude of the plutonium concentration. An alternative technique that offers the potential for enhanced understanding of plutonium is X-ray absorption spectroscopy (XAS), which targets characterization of oxidation state and local coordination geometry. Facilities for performing XAS of DOE waste samples include Los Alamos National Laboratory.

Additional potential means for addressing plutonium speciation (including the likelihood that elemental plutonium transforms to oxide or oxyhydroxide forms over time) include leaching demonstrations and solubility tests performed under real-waste conditions. Such approaches have been successfully utilized at SRNL for identification of various metal minerals in SRS sludge solids.

The recommended path forward is a collaborative effort between SRNL and PNNL, along with subject matter experts from other national laboratories as appropriate, to characterize plutonium utilizing spectroscopic analysis of real-waste samples coupled with applicable leaching/solubility testing.

Significance/Interfaces: Uncertainties surrounding the speciation and particle size of the plutonium in Hanford waste have resulted in technical issues being identified for mixing, transfer, and processing. Having a better understanding of the actual plutonium present may mitigate some of these concerns or at least provide a more clear understanding of how to address the concerns.

\subsection{Understanding Process Requirements}

Currently, a significant effort has been made for planning the development of the process requirements for both the tank farms and WTP for mixing and transfer of staged waste feed. The intent of this technical area is to augment those efforts to provide future opportunities to improve process performance. The planned approach will rely on full-scale testing to demonstrate the acceptance of WTP mixing systems. However, due to the cost of full-scale testing, limited process optimization can be performed. Scaling the performance of small-scale test results to full-scale requires extrapolation of the test results. Increasing the confidence of these extrapolations is beneficial to waste feed delivery mixing and sampling and is only possible through the use of prototypic scale results. This effort uses a detailed physical model to determine the linkage between small-scale testing, previous full-scale demonstrations, and planned mixing and sampling in waste feed delivery tanks to enable optimization of process performance.

\subsubsection{Scaling of Demonstration Tests}

Technology Gap: Jet mixing has only been performed in a few Hanford DSTs, and the only prototypic waste feed delivery mixing test that has been performed is AZ-101. Results for solids 
particle bottom motion and vertical suspension are available from this AZ-101 mixer pump test. ${ }^{40}$ While AZ-101 has a lower solids loading than typically planned for DST components in the Waste Feed Delivery system, an approach can be defined that utilizes this full-scale mixer pump test data in conjunction with the current scaled testing facilities and numerical simulation models to establish an understanding of scale performance of the fluid-jet mixing. Thus, the confidence of extrapolating small-scale test results to prototypic scale can be increased.

Approach: An outline to this approach is as follows:

1. Using a numerical simulation model (ParaFlow) define what available simulant components provide equivalent solids particle bottom motion and vertical suspension results to the AZ-101 prototypic mixer pump test.

2. Compare what fluid-jet velocity is required to replicate the prototypic scale solids particle bottom motion and vertical suspension results with the selected simulant from experimental testing in the current scaled testing facilities ( $4 \mathrm{ft}$. and $10 \mathrm{ft}$. diameter tanks) and the numerical simulation model.

3. With comparable results for Step 2, compare ParaFlow results against the specific test metric results of current scaled experiment that utilize Hanford Waste simulants at typical waste feed delivery solids loadings and rheology.

With comparable results for Step 3, use the numerical simulation model to predict what behavior would be expected in a prototypic waste feed delivery DST for the current scaled experimental test simulants and metrics.

ParaFlow simulates solid-liquid behavior using a multiphase flow solution for the transport and settling of the different suspended solid species, with separate fields to represent the settled solids in a sediment bed with a dynamic surface. This allows more accurate treatment of solids resuspension behavior than in typical commercial CFD models, such as FLUENT. This also is a distinction with commercial CFD tools. Another major advantage of the ParaFlow code is that it has very good scalability on large computer systems. This parallel performance enables results in practical timeframes for these necessarily transient simulations.

Recent ParaFlow simulations of the Waste Feed Delivery tank provide an example of the type of analysis that can be performed using this approach. The WTP Pretreatment Facility requires a uniform feed from each waste tank that consistently matches the tank average concentrations during the extraction process. This constraint requires an accurate method for determining the tank average through a limited number of samples during mixing. The model could be used to provide a meaningful prediction of the suspended solids behavior to guide both the sampling and extraction processes. A series of scaled experiments is being conducted to better understand the re-suspension behavior of different types of waste and could be used for further model validation.

ParaFlow has undergone comprehensive, but informal V\&V testing as part of its development history. For this application, ParaFlow is not a NQA-1 qualified code with formal V\&V. However, the proposed work scope would conduct preliminary feasibility studies to utilize ParaFlow's unique capabilities. If results support a promising approach, follow-on work will be required.

The anticipated deliverable would be a predictive model for scale-up behavior (e.g. mixing, resuspension) of different feed types based on small-scale testing. An additional goal would be to help evaluate sampling locations. 
Significance/Interfaces: Anticipating modeling needs for TOC and WTP, demonstration runs with ParaFlow were performed under EM-31 support in 2010-11. Termination of that program left planned work unfinished and inactive to date. For this tool to be available for addressing mixing and sampling in TOC waste feed delivery tanks, and in WTP non-Newtonian vessels, this task should be re-started early in FY13.

\subsubsection{Modeling of Non-Newtonian Fluids}

Technology Gap: Currently neither the Hanford Tank Farms nor WTP have a detailed modeling tool for mixing of non-Newtonian fluid slurries, yet this rheological condition is prominent in both. Basically this condition exists in high concentration slurries of finely divided solids and is both descriptive of the jet mixing process for settled sludge in the Tank Farms waste feed delivery tanks and in the concentrated solid slurries at the back end of the WTP Pretreatment Facility (specifically vessels UFP-2, VSL-HLP-0027 and VSL-HLP0028). While full-scale experiments will answer questions related to mixing and sampling in these vessels, a detailed model that accurately models the physics would allow early predictions of full-scale behavior. The model could facilitate test design, including placement of instruments, and aid in interpretation of test results. Moreover, a validated model would provide a means of predicting performance in similar vessels or the same vessel operating under different conditions. The key physical effects that are needed in the model include the ability to model Bingham yield stress fluids with discrete fields of solid particulate. The ability to model spargers is needed for WTP non-Newtonian plant vessels.

Approach: While a suitable commercial modeling tool is not available, there is a computer model at PNNL with nearly all of these capabilities. This is the ParaFlow code that is described under the approach in section 3.2.1. ParaFlow allows simultaneous modeling of non-Newtonian rheology with a settling particle field and settled solids layer. The ability to accurately model spargers is the only additional model required. Modeling of the gas bubble field would not be necessary for this application; instead the sparger's effect could be modeled by insertion of momentum sources. The sparger model would be based on literature and would be validated against previous, large-scale sparger testing done for $\mathrm{WTP}^{41}$.

The approach in this task would be to begin with models of the waste feed delivery tank while the sparger model is being included in the code. ParaFlow would be used to model the tank mixing of fluids with a range of Bingham plastic yield stress and consistency pairs to determine the slurry composition distribution and extent of fluid yielding within the tank for each fluid type. The local rheology may depend on local solids concentration and composition. For example, settling of solid particles may increase the yield strength of fluid near the bottom of the tank. Therefore, the multiphase transport will be coupled with the rheology distribution within the vessel. Once the sparger model is included and validated, simulations would begin on a selected WTP vessel with cases covering the expected range of rheological conditions and expected solids PSDD.

Completed models could then be used to answer questions, for example exploring locations and strategies for sampling.

Significance/Interfaces: This task helps answer questions regarding mixing and sampling in WTP non-Newtonian vessels containing spargers as the primary means for mixing. 
SRNL-STI-2012-00776

PNNL-22116

Revision 0

\subsubsection{Process Performance with Polydisperse Solids}

The variability of the Hanford waste makes predicting process performance even more difficult, given that performance models have typically been developed for mono-disperse particle slurries. Further, confirmation of system performance via testing only applies to the slurry tested. Thus, either through application of available models, or through testing, understanding performance with poly-disperse solids is significant.

As a specific example of the effect of poly-disperse solids for performance prediction, consider the well-known Zwietering correlation ${ }^{42}$ for the just suspended impeller speed in mechanically agitated vessels. The Zwietering correlation works well for a slurry with a single particle density. If, in a slurry with a distribution of solid density, the assumption is made that all particles are of a high density from the distribution, an unnecessarily conservative estimate of the power consumption will result from application of the Zwietering correlation. However, recent work has developed an approach for predicting the just suspended impeller speed via the Zwietering correlation for bimodal density slurries. ${ }^{43}$

Approach: Approaches similar to that used for the Zwietering correlation for poly-disperse solids with models that more closely relate to the waste storage, mobilization, transport, and processing (i.e. fluid jets, etc.) have not been identified from the literature. Recent studies with simple as well as complex well-characterized simulants, some of which were designed to represent Hanford waste characteristics, have been conducted for slurry pipeline transport.

Evaluation of the slurry pipeline transport data ${ }^{44,45}$, as well as recent data from the TOC Waste Feed Delivery Mixing and Sampling Program performance testing, can provide performance prediction approaches for poly-disperse solids. Although this evaluation would specifically consider available data for slurry pipeline transport, the similarity of the functionality of this metric with respect to particle size and density with the just suspended impeller speed in mechanically agitated vessels, analyzed for poly-disperse solids as referenced previously, and other metrics for particle mobilization and off-bottom suspension with radial jets without polydisperse data, there is potential for increased understanding of other pertinent Hanford waste handling and treatment processes.

Significance/Interfaces: The capabilities of the Tank Farm and WTP waste processing systems have limitations. Understanding system performance for the broad range of Hanford waste characteristics could have significant impact.

\subsection{Conditioning of Waste in the Tank Farm or within WTP}

\subsubsection{Size Reduction or Separation Techniques to Reduce or Remove Large Particles}

Technology Gap: The potential for large particles to be transferred from the campaign staged waste tank by the TOC to WTP is a concern. These large particles may accumulate in WTP tanks with pulse jets or cause line plugging. Accumulation of particles in vessels/tanks at the WTP is a criticality concern as documented in the DNFSB plan for vessel mixing. ${ }^{20}$

Approach: By reducing the particles to a more manageable size, mixing and transfer issues both in the Tank Farm and WTP should be more easily solved and criticality and settling may also be mitigated. Various methods and technologies for performing size reduction/separation have been studied or implemented for radioactive wastes over the years with different degrees of success. The national laboratories will provide an evaluation of existing radioactive experience with these 
methods. Alternative methods such as elutriation for particle separation or reduction of particle size through the use of slurry mixer pumps will be included in the evaluation. The evaluation report will help guide the contractors in evaluating their potential options. The laboratories can then work with the contractors to test the selected technology before implementation.

Significance/Interfaces: The potential for large particles in the Hanford waste creates several safety and operational concerns in the Tank Farm and the WTP Pretreatment Facility. Elimination of these particles could mitigate several concerns. This approach would also be applicable to direct feed HLW options.

\subsubsection{Enhanced Mixing Systems for Staging Feed}

Technology Gap: The TOC must be able to remove solids from waste tanks and transport them to downstream waste tanks and the WTP. To obtain a representative sample and minimize process variation, the tanks should be well mixed across a range of sludge properties. Ideally, the tank would also be capable of blending different waste types to optimize processing and the glass formulation. The TOC has been conducting pilot-scale testing to assess the ability of their mixer pumps to suspend and transfer solid particles from waste tanks to the WTP (see Section 2.1.1).

The TOC has demonstrated in pilot-scale testing that they can adequately obtain representative samples using Isolok ${ }^{\circledR}$ samplers of the waste being transferred to WTP. However, the TOC has not effectively demonstrated the ability to mix the tanks sufficiently across the anticipated slurry property range to collect representative samples of the DST. Representative samples are needed to qualify the feed for WTP. Additionally, the testing to date has focused on the use of physical simulants rather than chemical simulants.

At the SRS, homogeneity, mixing, and representative sampling have been demonstrated through the use of four quad volute pumps for extended duration (i.e., 8 to 36 hours) and over a rheology range anticipated for DWPF.

Approach: For either the existing DST or for potentially new tanks, the following approach should be applied to address any mixing deficiencies:

1) Identify the mixing objective - blending miscible fluids, bulk sludge mixing, particle suspension, or heel removal.

2) Determine the relevant properties for the material to be mixed - density, particle size, rheological properties, settling behavior.

3) Identify the motive force for mixing using calculations/models. $46,47,48,49,50,51,52,53,54$ to determine the equipment needs (e.g. jet mixers, spargers, bubblers ${ }^{55}$ )

4) Demonstrate and/or evaluate the system on a sufficient scale across the anticipated range of properties.

5) Verify effective sampling through demonstrating homogeneous mixing.

Significance/Interfaces: Existing technologies and programs are in place to test the efficiency for the current configuration. Should the opportunity arise to build new tanks or install additional mobilization pumps or change the existing mixing mode, this information would be available.

\subsubsection{Washing or Pretreatment of HLW Sludge in the Tank Farm}

Technology Gap: At WTP, solids processing has been combined with supernate treatment at the start of the pretreatment process. This complicates some of the design and operations in the Pretreatment Facility due to concerns over Al precipitation and solids settling/mixing. It also 
requires numerous cycles of the ultrafiltration unit. At SRS, processing of solid streams is separated from the processing of supernate streams by performing washing, aluminum dissolution and other processing steps on the solids fraction in the tank farm. The processing of HLW in the Tank Farm would minimize the requirements for the Pretreatment Facility to process solids, increasing the rates that LAW could be processed through the Ultrafiltration (UF) and ion exchange (IX) processes. Solids would not be completely eliminated from the WTP as the HLW and LAW recycle streams from the vitrification facilities contain significant solids fractions.

Approach: The laboratories can assist in evaluating options for performing solids processing in the Hanford tank farm. Two tasks are proposed.

Task 1 - Evaluate Existing Direct HLW Plans: The Hanford contractors have already completed preliminary evaluation of direct HLW vitrification bypassing the Pretreatment Facility and performing some of the sludge processing steps elsewhere. These proposals should be reviewed and opportunities to provide technical assistance or insert new technologies in advance of program decision points identified. These evaluations should focus on the lessons learned for washing and leaching of sludges in the waste tanks at SRS.

Task 2 - LAW Treatment in the Tank Farm: Supernate treatment at SRS consists of Sr/TRU removal using monosodium titanate (MST) adsorption followed by filtration to remove solids, while at Hanford Sr/TRU is removed via co-precipitation processes followed by filtration. Subsequent cesium removal is then performed. At SRS, cesium removal utilizes solvent extraction, while Hanford utilizes cation exchange. In tank treatment using the Small Column Ion Exchange (SCIX) concept has been demonstrated using monosodium titanate and crystalline silicotitanate for SRS. Adaptation of similar technology to Hanford could provide a means for LAW treatment before start-up of the Pretreatment Facility or provide supplemental treatment. The contractors have been evaluating these treatment options. The laboratories have made progress on evaluation of these technologies. Should this option become probable, the laboratories could identify the feasible technology for implementation.

Significance/Interfaces: Minimization of solids processing in the WTP by performing pretreatment of the HLW solids in the Tank Farm, if feasible, would reduce the concerns of processing with the pulse jet mixing systems. Cesium removal at or near tank also precludes the use of the Pretreatment facility. Potentially, these processing options represent a significant improvement in the schedule for start-up of vitrification of HLW and LAW streams at Hanford. This option could allow processing of selected wastes prior to the startup of the WTP Pretreatment Facility.

\subsubsection{Al Dissolution in the Tank Farm and Pretreatment Facility}

Technology Gap: The WTP flowsheet utilizes aluminum dissolution during pre-treatment to divert a significant fraction of the HLW feed to the LAW stream. Currently, the WTP contractor will perform Specification 12 testing $^{26}$ for each staged waste campaign to determine the nominal Al dissolution parameters. Performing aluminum dissolution in Hanford's Tank Farm, instead of in a separate pre-treatment facility, offers potential advantages from the perspectives of efficiency, flexibility, and facility requirements. SRS has effectively performed aluminum dissolution in their Tank Farm, removing $60-75 \mathrm{wt} \%$ of solid-phase aluminum at temperatures ranging from 60 $70{ }^{\circ} \mathrm{C}$ and time periods ranging from 26-46 days. In the SRS cases, boehmite was the primary mineral form and gibbsite was a minor contributor. Given the relatively slow dissolution kinetics of boehmite, there is the expectation that dissolution of solids containing higher gibbsite content 
could potentially be performed at lower temperatures and/or over shorter durations. Regardless of whether WTP aluminum dissolution is performed in the Pretreatment Facility or in the Tank Farm, there is the need to generate applicable real-waste aluminum dissolution data, hone the dissolution requirements, understand the downstream impacts and in-tank impacts, and select the dissolution conditions and locale that are most beneficial to efficient operations.

Approach: Real-waste aluminum dissolution testing has been performed to develop the baseline flowsheet for the WTP; however, additional testing would be needed to implement this opportunity. This additional testing would involve the performance of real-waste aluminum dissolution demonstrations that provide a baseline for: a) verifying validity of processing expectations/projections; b) honing understanding of dissolution response and requirements; c) identifying potential processing issues; d) identifying potential downstream impacts; and e) comparing the pros and cons of performing aluminum dissolution in the Pretreatment Facility versus the Tank Farm. Given the experience gained through previous real-waste aluminum dissolution demonstrations and SRS in-tank deployment, the national laboratories are prepared to assist in the selection of effective test strategies; support development of experimental methods and laboratory equipment; and collaborate with respect to existing test results, operational data, process knowledge, and insights.

Significance/Interfaces: Due to the large volume of high Al containing sludges and the large volume of caustic required for treatment, optimization of the process is desirable. Operations in the Pretreatment Facility are limited and any optimization would be beneficial for the Pretreatment Facility or for options such as Direct HLW vitrification. The current requirements to maintain facility temperature $45^{\circ} \mathrm{C}$ may be able to be relaxed if dissolution is done elsewhere.

\subsubsection{Waste Feed Rheology Control}

Technology Gap: Waste slurries exhibit wide variations in rheological properties. As discussed in the previous sections, the tank farm operations involve mixing, blending, and transporting through pipelines where controlling rheological properties of the slurries is pivotal. The control of the rheological properties becomes much more critical whenever challenging conditions are introduced (e.g., unexpected process fluctuations and slurries having very challenging rheological properties). Similarly, the Pretreatment and Vitrification Facilities alter physicochemical characteristics of waste slurries (e.g., changes of chemical compositions, solids content, and particle sizes due to dissolution and addition of glass forming chemicals), and, subsequently, a drastic change of rheological properties may be expected. Rheological properties of the waste slurries are strongly correlated with particle interactions; a delicate balance between repulsive and attractive particle interactions dictates the rheological properties. Therefore, a key strategy to control the rheological properties, via understanding/manipulating particle interactions, is required.

Approach: Two approaches to control the rheological properties can be: (1) an indirect change of particle interactions via changes of physicochemical characteristics such as $\mathrm{pH}$ and solid contents and (2) a direct change of particle interactions by adding a small amount of chemical additive called a rheological modifier. Figure 3-1 shows an example of the impact of rheological modifiers on a physical slurry simulant. While both approaches are plausible, the former might not be a viable option since it can cause additional issues. In general, a rheological modifier (typically weak acids, carboxylates or non-ionic surfactants) would not alter intrinsic physicochemical characteristics of the slurries (and thus further processes) appreciably due to its effectiveness with a small amount; $<5000 \mathrm{ppm}$ would be sufficient based on previous studies. Its 
effect would be relatively instantaneous because it does not involve any chemical reactions. Further, special thermodynamic conditions such as higher temperatures are generally not needed. Previous studies showed that weak carboxylic acids (e.g., citric acid) are promising rheological modifiers (decreasing by $\sim 70 \%$ of yield stress for the AZ-101 simulant). ${ }^{56}$ But the performance was dependent on various physicochemical properties of particles (e.g., composition and particle size distributions) as well as types of rheological modifiers. Such details have not been completely investigated yet.

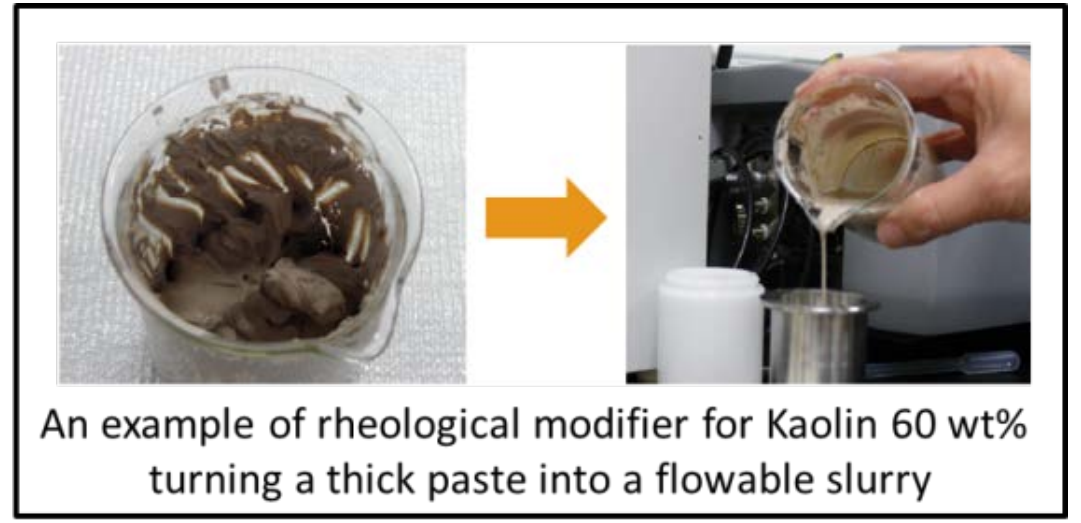

Figure 3-1. Example of Impact of Rheological Modifier.

In order to obtain a clear picture for rheological control under the wide variety of waste slurries and processing conditions, systematic research should start with simple model slurries having controlled physicochemical parameters (e.g., particle sizes (distributions), solid contents, and salt concentrations) relevant to representative waste slurries and processing conditions. Such model simulant slurries should be selected to study the effect of the coupling between physicochemical parameters. Then, rheological modifiers need to be thoroughly studied with the various model slurries to understand the effect of physicochemical characteristics of slurries on rheological properties and the performance of rheological modifiers. Selected rheological modifiers would then be applied to existing waste simulant slurries and actual waste slurries; such results can be interpreted and analyzed from detailed understanding with the model slurries. Additionally, downstream impacts on other waste processing facilities would be studied.

The anticipated deliverable is a suite of rheological modifiers to enhance Tank Farm and WTP facility processing.

Significance/Interfaces: The research will provide a reasonable and promising strategy to control the rheological properties with accommodating variations of the slurries and processing conditions, which, in turn, could mitigate the significant processing problems associated with both tank farm operations and the Pretreatment/Vitrification Facilities. Furthermore, the research may provide a reasonable solution for cost-effective processing as to increased throughput for the WFD and WTP facilities. 
SRNL-STI-2012-00776

PNNL-22116

Revision 0

\subsection{WTP Process Qualification}

This section is divided into three subsections and discusses the aspects of the WTP Waste Feed Qualification program. Section 4.1 addresses the sample requirement needs for the TOC Staged Feed Tank and the WTP process vessels. Section 4.2 discusses the applicable waste acceptance criteria/DQO analyses of staged feed. Section 4.3 addresses the pretreatment operations and the associated waste feed qualification program. The technology gaps or improvement opportunities addressed in sections 4.1 through 4.3 are summarized in Table 4-1.

Table 4-1. Technology Gaps or Improvement Opportunities for Feed Criteria Development

\begin{tabular}{|l|l|}
\hline Section & Technology Gap/Improvement Opportunity \\
\hline \hline 4.1 - Representative Sampling of the & Unknown Sample Size for Waste Feed \\
Feed Staging Tank and Process & Qualification Program \\
\cline { 2 - 2 } Vessels & $\begin{array}{l}\text { Representative Sampling for Waste Feed } \\
\text { Qualification Program }\end{array}$ \\
\cline { 2 - 2 } & $\begin{array}{l}\text { Isolok }{ }^{\mathbb{B}} \text { Sampling System for Obtaining the Waste } \\
\text { Feed Qualification and Vessel Samples }\end{array}$ \\
\hline $\begin{array}{l}4.2 \text { - Waste Acceptance } \\
\text { Criteria/DQO Analyses of Staged }\end{array}$ & Extensive Analytical Requirements \\
\cline { 2 - 2 } Feed & Analytical Gaps and Improvements \\
\cline { 2 - 2 } $\begin{array}{l}4.3 \text { - Process Qualification Program } \\
\text { with Waste Feed Qualification } \\
\text { Sample }\end{array}$ & Hydrogen Generation Rate Measurement \\
\cline { 2 - 2 } & Pretreatment Process Demonstration \\
\hline
\end{tabular}

\subsection{Representative Sampling of the Feed Staging Tank and Process Vessels}

As discussed in section 2.1.1, the TOC will be required to take a representative sample for delivery to WTP to support the waste feed qualification program. This section addresses the technology gaps associated with taking a representative sample for the program.

\subsubsection{Unknown Sample Size for Waste Feed Qualification Program}

Technology Gap: The required sample volume for the WTP waste feed qualification program is currently not defined. The specific requirements of the waste feed qualification program were outlined in section 2.2 and require analyses of a large suite of analytes and bench-scale demonstration of the Pretreatment Facility processes on each waste feed qualification sample. Given that the scaled equipment has not been designed and tested for the demonstration of the pretreatment processes, the required sample volume is not known.

Once the required sample volume is determined, the logistics for pulling and transferring the sample to the qualifying laboratory can be defined. Depending on the size and number of sample containers, the ability to accept and handle the sample in an existing hot cell may also be an issue. Samples of HLW up to 25L were taken, transported, and handled at SRS to support DWPF so precedent does exist for handling large samples.

Approach: WTP is investigating the required size of the bench-scale equipment for performing the waste feed qualification demonstrations as part of the Phase 2 qualification program ${ }^{24}$. Once the waste feed qualification equipment is defined, a sample volume, shipping container, transportation method, and facility handling protocol can be determined. The national 
laboratories are already involved in defining the equipment size and can provide assistance in solving the other challenges once the sample size is defined.

The proposed deliverable would be definition of the sample size to meet the goals of the waste feed qualification program.

Significance/Interfaces: The determination of the sample volume is on-going work funded by WTP that has been deferred pending resolution of the Pretreatment Facility path forward. This information is still needed with alternative WTP operations such as Direct LAW or HLW. Resolution of this gap may impact the TOC sampling protocol, along with the associated cost/schedule, which is currently being worked by the TOC.

\subsubsection{Representative Sampling for Waste Feed Qualification Program}

Technology Gap: A potential issue with Hanford DST samples is the extent of mixing that is obtained in a million gallon tank and its subsequent impact on obtaining a representative sample (see Section 2.1.1). If mixing is not homogeneous or fast settling solids are present, issues could arise with the TOC's attempt to obtain a representative sample from the batch to be transferred for waste feed qualification or in WTP's attempt to take samples from vessels within the Pretreatment or Vitrification Facilities.

Approach: The term "representative sample" needs to be defined. The definition needs to be consistent between the TOC and WTP contractors to ensure continuity. As was done with SRS and the DWPF, the national laboratories can help with outlining the strategy for defining representative sampling. The laboratory strategy would include 1) definition of the needed accuracy, 2) a known composition for comparison, 3) prototypical set-up of the sampling system, 4) equivalency demonstrations between samples taken from the tank and the sample system, 5) determination for location of sampling, 6) testing over the expected range of conditions, and 7) consideration of the uncertainty associated with sampling and analytical. The strategy will consider the applicability of the Pitard-Gy sampling philosophy given recent inquiries by the DNFSB and will consider strategies already successfully deployed at SRS.

Significance/Interfaces: The foundation of facility operations and the HLW product qualification program rely upon the use of representative samples. If this does not occur, then facility operational issues may be more frequent and the demonstration of wasteform compliance will be difficult.

\subsubsection{Isolok ${ }^{\circledR}$ Sampling System for Obtaining the Waste Feed Qualification and Vessel Samples}

Technology Gap: The TOC is planning to use an Isolok ${ }^{\circledR}$ sampler for obtaining a large waste feed qualification sample on each campaign batch, while the WTP is planning to use Isolok ${ }^{\circledR}$ samplers throughout the WTP facilities. The Isolok ${ }^{\circledR}$ will retrieve the sample from a sample loop that is fed from the tank or vessel while the contents are being mixed. Typically an Isolok ${ }^{B}$ sampler is used to retrieve small samples, $\sim 30 \mathrm{~mL}$. The technology is currently being used at DWPF to take small $(<20 \mathrm{~mL})$ samples for process and product control. However, for the SRS Tank Farm sludge batch qualification sample or routine Tank Farm process control slurry samples, large samplers $(1$ or $3 \mathrm{~L})$ or dip samples $(80$ or $200 \mathrm{~mL})$ are taken directly from the tank volume after thorough mixing.

Typically, the Isolok ${ }^{\circledR}$ will take a $\sim 5.3 \mathrm{~mL}$ sample on each piston cycle. For the WTP waste feed qualification sample, a large volume sample will be needed and the Isolok ${ }^{\circledR}$ piston will cycle 
many times over an extended duration. Obtaining the waste feed qualification sample by this method may prove to be very costly and inefficient to the facility. The repair or replacement of the Isolok ${ }^{\circledR}$ in a radioactive environment will add to the operational cost and result in possible schedule delays.

Approach: WRPS has a full-scale Isolok ${ }^{\circledR}$ sampling test flow loop and testing is ongoing in the Monarch Facility in Pasco, WA. However, it is not clear whether this testing addresses the wear of the Isolok ${ }^{\circledR}$ under prototypical conditions. In any case, the feasibility of taking this large sample needs to be demonstrated before implementation in a radioactive environment.

The laboratories will work with the Hanford contractors to develop and test a back-up sampling system should the Isolok ${ }^{\circledR}$ not prove viable because of the sample size requirements. Some history of pulling larger samples exists since they were pulled for the RPP programs performed in the late 1990s/early 2000s and for SRS DWPF samples.

For smaller samples, the Isolok ${ }^{\circledR}$ has been demonstrated to be viable for well mixed tanks across a broad range of slurry properties. The WTP has tested these systems and they will need to be demonstrated for waste feed qualification and process control in the expected configuration. The laboratories can help define the necessary strategies and assist in the review of the data as was done for the SRS.

Significance/Interfaces: The Isolok ${ }^{\circledR}$ systems are currently being planned to be used throughout the Tank Farm and WTP facilities. Demonstration of applicability across the range of waste conditions expected and in the particular control applications needs to be completed before startup to allow time for any design modifications.

\subsection{Waste Acceptance Criteria/DQO Analyses of Staged Feed}

The suite of required analyses to meet the WTP waste acceptance criteria and DQO were discussed in section 2.2. This section discusses the technology gaps associated with those analyses.

\subsubsection{Extensive Analytical Requirements}

Technology Gap: The existing feed qualification program requires quantification of a very extensive set of physical parameters and chemical constituents. This list includes about 177 regulatory organic constituents. Specifically, over two hundred WAC/DQO parameters will be quantified, including a wide range of elemental, radiological, and organic constituents if the number of organic constituents does not significantly decrease following the completion of the WTP Risk Assessment required by the dangerous waste permit. The resource requirements for analyzing the full suite of constituents will be significant, due to complexities associated with the high metal-content/high rad content sample matrices and the high chemical separation decontamination factors needed to effectively measure many of the constituents. Given the large number of parameters being quantified, coupled with the inherent challenges of characterizing constituent concentrations ranging over several orders of magnitude (up to eight orders of magnitude for radionuclides), completion of all analyses within the required turnaround time is expected to be extremely difficult. Experience in the context of qualifying feed for the SRS DWPF, Saltstone, and tank closure suggests that completion of such a large suite of parameters will likely be wrought with unplanned resource demands related to method development work, instrument optimization maintenance, and repeat analyses using alternative chemical separation methodologies. Some of these analyses are completed within 90 days of receipt, while others can 
take closer to 180 days. The frequency of the 90 day samples is once a quarter and has more routine analytes with a smaller list than Hanford's. The other samples have an analyte list that changes with the current customer needs and requires more close coordination. Recognizing that a maximum of 180 days are available to complete the entire waste feed qualification process and 30-60 days will be required for data review, analysis, reporting, and comment incorporation means that all sample analyses will actually need to be completed in the 120-150 day range. SRNL experience indicates that successful completion for all of the analytes of interest in this time frame will be extremely challenging.

Approach: Three parallel approaches are recommended for easing the resource challenges associated with the analytical requirements and supporting completion of the waste feed qualification activities in the allotted timeframe. First, an assessment of all existing WAC/DQO parameters should be performed, with the intent of removing any parameters that are not absolutely necessary, based on the current operational and regulatory requirements. Second, a concerted effort should be made to minimize the number of parameters requiring quantification via sample analysis. Where applicable, technical relationships and process knowledge should be used to quantify parameters via calculation in lieu of sample analysis. Third, sample analyses that are most labor intensive and time consuming should be initiated first, to assure completion by the deadline. This would be an expected outcome of the waste feed qualification program currently funded by WTP. The national laboratories will assist WTP in applying these three approaches to streamline the WTP feed qualification program based on the analytical experience gained supporting DWPF and in analyzing Hanford samples. Technical justification for the change and defense will be provided.

Significance/Interfaces: Due to the associated cost and time of doing analyses over the life of the facility, any reduction will be beneficial. The information gained from analyzing all of the constituents is not evident since WTP is not using all of this data to qualify the glass product or in processing of the feed. The requested analyses should only be those required.

\subsubsection{Analytical Gaps and Improvements}

Technology Gap: As discussed in section 2.2, SRNL performed an initial review of the WTP waste feed qualification program and identified four gaps that are being worked. Additional analytical gaps associated with waste feed qualification were identified in meetings with the TOC and WTP for this strategic effort. Examples include the need to: a) speciate low concentrations of plutonium, b) effectively characterize an extensive suite of organic compounds and c) potentially characterize ${ }^{231} \mathrm{~Pa}$. In addition, based on SRNL experience for SRS salt and sludge batch qualification, there is the expectation that as WTP waste feed qualification analyses begin, there will be a considerable amount of unplanned method development/improvement work that is necessary, given the complexity of the sample matrices, the extensive suite of constituents, and the large range of constituent concentrations. The need for filling analytical gaps and improving analytical methods will likely impede WTP's ability to stay on schedule and meet waste feed qualification requirements.

Approach: SRNL has initiated testing focusing on low level plutonium speciation and plans to continue this work in the future (see section 3.1.5) as part of its Tank Closure program. Performing joint testing in this area, with the objective of understanding Hanford and SRS plutonium speciation, will benefit both sites and facilitate resolution of WTP's plutonium uncertainties. 
SRNL-STI-2012-00776

PNNL-22116

Revision 0

In addition, the national laboratories researchers will work with the WTP laboratories, supporting development of organic compound/complexant characterization methods meeting WTP program needs to improve process time.

Based on SRNL and PNNL's experience honing analytical methods for DWPF sludge batch qualification (and for Tank Closure residual solids characterization), the laboratories are prepared to support WTP's other analytical method development needs and assist in analytical troubleshooting - particularly in the areas of elemental and radioisotope analyses.

With the potential start-up of the WTP treatment facilities several years down the road, some of the existing analytical equipment will become obsolete or improvements in techniques could be made. The laboratories will continue to work with WTP to identify and implement any applicable changes.

Significance/Interfaces: It will be better to discover any problems before or during facility startup than during the 180-day waste feed qualification period or during actual operations. Given the laboratories' history of meeting Hanford, DWPF and Tank Closure characterization needs, there is the expectation that collaboration with the WTP laboratories will facilitate development of a successful analytical program.

\subsubsection{Hydrogen Generation Rate Measurement}

Technology Gap: The current qualification strategy requires measurement of HGR for the incoming HLW and LAW feeds as part of the waste feed qualification program. In addition, measurement of HGR is specified for selected streams during waste feed qualification of the pretreatment process. The generation rates are typically very low and are difficult to measure in a radioactive environment on small samples.

Approach: The WTP has currently tasked SRNL to develop the equipment and techniques necessary to measure HGR on the waste feed qualification sample. However, using existing models to calculate the HGR for incoming feeds would eliminate measurement of HGR during waste feed qualification. The existing models have been adapted for use in the WTP and studies have shown that the HGR models provide bounding values for the WTP tank waste. ${ }^{57}$ Use of the calculated values would reduce sample volume requirements during waste feed qualification as well as eliminate the cost of performing the HGR measurement. Use of the calculated HGR would align with current SRS practice for radiolytic hydrogen. An order of magnitude difference between the HGR Action Limit and the expected HGR rates is predicted for HLW as documented in the One System Gap Analysis ${ }^{1}$.

During the evaluation to replace the measurement with a prediction, the amount of conservatism should also be evaluated in the existing HGR controls at WTP and a determination made on what steps are needed to reduce the level of conservatism.

The amount of hydrogen evolved from LAW streams is much lower than the HLW streams. Given that the primary concern for HGR in the WTP is the entrapment of hydrogen in settled solids, the LAW either provides much less risk than HLW since the amount of solids in the stream is very small or because the hydrogen from the LAW will be much smaller than the hydrogen from the HLW if the LAW is combined with a HLW stream containing solids. The laboratories can assist in providing the technical basis to eliminate this measurement through 
SRNL-STI-2012-00776

PNNL-22116

Revision 0

review of existing data and documentation of the bounding nature. Demonstrations of a bounding nature could be performed on select radioactive samples to strengthen the case if necessary.

The evaluations would be documented in a deliverable with the recommended path forward or implementation plan.

Significance/Interfaces: Given the time constraints for waste feed qualification of each batch for WTP processing, elimination of non-value added scope from the waste feed qualification effort should be considered. Given the amount of conservatism in the design basis and in the HGR calculation, measurement of HGR during waste feed qualification is not expected to be beneficial if subjected to a cost-benefit analysis.

\subsection{Process Qualification Program with Waste Feed Qualification Sample}

The process steps that will need to be demonstrated for the WTP waste feed qualification program were outlined in section 2.3. This section provides recommendations on changes to the program. In order to implement these changes, technology gaps and the associated approaches to close the gap have been identified.

\subsubsection{Pretreatment Process Demonstration}

Technology Gap: Demonstration of the Pretreatment Facility processes on a small scale is part of the baseline waste feed qualification program, as well as the measurement of a large suite of analytes. A discussion on reducing the number of analytes to be characterized on the qualification sample was provided in section 4.2. Based on the EFRT recommendation, WTP has agreed to demonstrate each step of the pretreatment process on a bench-scale with the waste feed qualification sample for each campaign. This demonstration must be completed within 180 days prior to feed delivery to the WTP. As projected, the qualification testing will have to be performed at least twice a year. With waste stored in 177 HLW tanks, this effort will be very work intensive for the life of the WTP Facility. The high work load in this short turn around may impact the successful operation of the WTP Facilities.

SRNL has already completed a preliminary review of the demonstration aspect of the qualification and the results were documented in SRNL-STI-2011-00723 ${ }^{58}$. SRNL identified potential concerns with waiting until radioactive operations to perform this testing and the WFA\&PQ team concurred with the concerns, as well as concerns with the potential short time frame for completing the task particularly if parameter processability is in question from the test data.

Additionally, limited testing of the pretreatment processes has been completed but only with a restricted set of simulants and real waste samples and likely not at a scale required for shielded cells demonstrations. The determination of waste processability using standard laboratory instruments and techniques in a hot cell environment will need to be demonstrated before radioactive start-up of the WTP in order to ensure that the necessary processability parameters will be determined.

Approach: As part of the process to close the pretreatment process demonstration gap before start-up, WTP is currently funding SRNL to develop the necessary scaled equipment to demonstrate the pretreatment processes over a range of simulants to test equipment operations. Therefore, the risk of not having applicable instruments and techniques for radioactive operations is mitigated through this contract. However, this does not mitigate the long-term cost associated 
with performing extensive qualification testing with each campaign or operational risk of determining potential processing issues with little time to mitigate them. These risk reduction techniques usually occur through demonstration over a range of properties in prototypical equipment using simulants. Scale-up with simulants is then typically performed, along with validation with radioactive samples, to ensure minimal production risks with radioactive wastes.

To close this gap, the national laboratories can provide a critical review of the existing pretreatment process data to determine process gaps. Simulant testing could then be performed to fill the gaps and define the operational bounds of the processes. The review and testing should also identify any gaps from a scaling perspective before final construction is completed of the Pretreatment Facility. By defining the bounds before the facility start-up, verification of waste processability should be more straight-forward during waste feed qualification. The review and testing would help determine if reduction/streamlining in the overall waste feed qualification testing program is possible.

If streamlining is not viable before start-up, the national laboratories can help set the stage for elimination or reduction of process testing as the qualification program matures and radioactive data becomes available.

Significance/Interfaces: Demonstration of the WTP processes with each campaign batch may prove to be costly and may not identify all the gaps until it is too late for facility operations to address. Performance of the activities identified in this task can help reduce the associated risk and close pretreatment process gaps.

\subsubsection{Elimination of Glass Analyses Post Glass Former Addition in the Waste Feed Qualification Process}

Technology Gap: The final step in the WTP process qualification program is the use of the glass composition-property models to identify the blend of waste and glass formers that will meet both process and product performance constraints using models appropriate to the QGCR for the campaign batch. This blend will be demonstrated to produce a feed for rheology measurements and a glass for analyses. As currently outlined, the mixture (melter feed) would again be sampled and analyzed before being melted to produce a glass product. The model assessment would then be repeated to demonstrate the QGCR for the feed campaign. In addition, the vitrified product would be evaluated for phase homogeneity or crystalline phase separation. ${ }^{59}$ These assessments would not include verification through glass fabrication and testing that the models apply since the acceptability of the feed is considered for each MFPV during processing.

Approach: As currently outlined, the waste feed qualification program would simply serve to provide a sample for subsequent analyses and as a confirmation that the batching process used during waste feed qualification was successful in targeting the glass composition of interest. Given the technical foundation of the HLW product qualification program is based on applicability of the glass formulation algorithms to the full range of waste to be processed through WTP and no property measurement are being made, the laboratories recommend elimination of this redundant elemental analyses. No new information would be gained from this sample since no additional processing steps are being performed. The Laboratories also recommend relaxing the constraint for phase homogeneity or separation given the nonrepresentativeness of this sample to the process. Once the samples are shown to be equivalent, the laboratories can provide a position paper describing the basis for eliminating the measurement. 
SRNL-STI-2012-00776

PNNL-22116

Revision 0

Significance/Interfaces: The proposed approach has the potential to impact the waste feed qualification program and reduce the duration and costs with minimal risks due to the redundant nature of the measurement. 
SRNL-STI-2012-00776

PNNL-22116

Revision 0

\subsection{HLW Product Qualification}

This section addresses the technology gaps and approaches for the HLW Product Qualification and is focused on those efforts required to qualify the HLW waste form. Section 5.1 discusses an approach to initiate the HLW product qualification efforts in the Pretreatment Facility, which would reduce the analyses required in the HLW Vitrification Facility. Section 5.2 addresses the number of samples to be analyzed in the HLW Vitrification Facility. Section 5.3 discusses the need for expansion of the glass composition envelope for the complete waste inventory. Section 5.4 addresses potential studies that could be initiated because of the change in the HLW repository and approaches to reduce conservatism in the process with the existing HLW Waste Acceptance Product Specifications. The technology gaps or improvement opportunities addressed in sections 5.1 through 5.4 are summarized in Table 5-1.

Table 5-1. Technology Gaps or Improvement Opportunities for Feed Criteria Development

\begin{tabular}{|c|c|}
\hline Section & Technology Gap/Improvement Opportunity \\
\hline $\begin{array}{l}5.1 \text { - Use of VSL-HLP-0027/0028 } \\
\text { for HLW Product Qualification }\end{array}$ & $\begin{array}{l}\text { Develop, Demonstrate, and Implement Strategy to } \\
\text { Demonstrate Homogenous Mixing }\end{array}$ \\
\hline $\begin{array}{l}5.2 \text { - Basis for Number of Samples } \\
\text { for Analyses }\end{array}$ & $\begin{array}{l}\text { Review the Basis for Number of Samples and } \\
\text { Recommend Changes as Necessary }\end{array}$ \\
\hline \multirow[t]{2}{*}{$\begin{array}{l}5.3 \text { - Expansion of the Glass } \\
\text { Composition Envelope }\end{array}$} & $\begin{array}{l}\text { Broaden the Existing Glass Models to Cover Full } \\
\text { Range of Anticipated WTP Wastes }\end{array}$ \\
\hline & $\begin{array}{l}\text { Develop Glass Models for Specific Compositional } \\
\text { Areas by Waste Type }\end{array}$ \\
\hline \multirow{6}{*}{$\begin{array}{l}5.4 \text { - Potential Change in Repository } \\
\text { Requirements and Compliance } \\
\text { Programs }\end{array}$} & Review Existing Requirements \\
\hline & Radioactive Qualification Demonstrations \\
\hline & Change in HLW Glass Canister Thickness \\
\hline & RW-0333P Quality Assurance Requirements \\
\hline & Required Analyte Reporting \\
\hline & $\begin{array}{l}\text { Reducing Conservatism in HLW Wasteform } \\
\text { Compliance }\end{array}$ \\
\hline
\end{tabular}

\subsection{Use of VSL-HLP-0027/0028 for HLW Product Qualification}

Technology Gap: The current HLW compliance strategy calls for: 1) waste to be transferred from VSL-HLPV-0028 to the MFPV, 2) sampling and analyses of the waste (including melter feed heel) in the MFPV, 3) formulation of glass based on elemental analyses, 4) addition of glass formers to the MFPV to fabricate the target melter feed, 5) sampling and analyses of the melter feed in the MFPV, 6) calculations of the resulting glass properties before release of the MFPV batch, and 7) transfer of the MFPV batch to the MFV. These 7 processes are to be performed for each and every MFPV batch, which contains roughly 4500 gal of waste and 5500 gal of melter feed. This approach was based on the challenge to demonstrate well-mixing of large volumes of HLW sludge in VSL-HLP-0028 or VSL-HLP-0027b. The process requires 12 samples (elemental analyses from 4 HLW samples and product compliance analyses from 8 melter feed samples) to be analyzed for over 100 analytes for each batch. Extremely short turn-around-times are required for a few analytes. To support the short turn-around-times, WTP funded SRNL and PNNL to develop the Laser Ablation-Inductively Coupled Plasma (LA-ICP) methodology for implementation in the WTP Laboratory. This methodology has been successfully demonstrated in the shielded cells at the Hanford site laboratory using actual tank waste samples. 
A significant improvement in facility operation and laboratory load can be realized if some of the qualification steps could move from the 4500 gal MFPV to the 81,000 gal HBV batch (VSLHLP-0028 or VSL-HLP-0027b). The challenge is in demonstrating that one of these vessels is sufficiently well mixed to obtain a representative sample. These are pulse-jet mixed tanks in the Pretreatment Facility with similar design and were not previously required to be well mixed.

Although limited samples would still be required to confirm the glass former additions to the MFPV, the compliance approach could be based on the waste composition from HBV and masses of glass formers transferred. This would significantly reduce the amount of sampling and analyses by roughly $10 \times$ and would reduce the time required to qualify each batch for processing. This revised approach is similar to the "macro-batch" approach used at the DWPF although at a smaller scale ( $\sim 250,000$ to $1,000,000$ gallons compared to 81,000 gallons).

Approach: In order for this approach to be implemented, homogeneous mixing and representative sampling would need to be demonstrated in VSL-HLP-0027/28. The work activities would be:

1) Develop a conceptual strategy on how to implement the two HLP vessels to accomplish this work

2) Perform a cost benefit analysis to assess the order of magnitude of potential savings.

3) Update ParaFlow model to account for the impact of spargers (see section 3.2.2) and consider the HLP-0027 and -0028 vessel designs.

4) Perform modeling to determine how well mixing can be obtained by non-Newtonian HLW slurries in the vessel chosen as the waste compliance sample point.

5) Conduct or use results from large-scale mixing and sampling tests to verify the ParaFlow results. The model results will be used to estimate the mixing and sampling uncertainties expected from VSL-HLP-0027b or -0028 for use in determining the impacts of the proposed change on the QGCR size.

6) Perform waste form qualification activities to demonstrate the acceptability of waste forms produced by the revised strategy as part of cold runs or product qualification activities before start-up.

7) Work with WTP to revise the Waste Form Compliance Plan and the Qualification Report with the new strategy and data.

Significance/Interfaces: By changing the operating strategy and demonstrating the ability to generate a relatively constant feed with a representative sample from the two HLP vessels, the WTP should be able to reduce the sampling requirements and the need for extremely short turnaround-times on HLW samples. The strategy should dramatically reduce the radionuclide analyses with each MFPV batch and it should minimize the analyses of minor elemental constituents. The overall turn-around-time should be reasonable and the HLW compliance strategy should be simplified. The strategy should also allow more control over the mixing and addition of glass forming chemicals since they should remain more consistent over the 81,000 gallon batch. A similar approach should be pursued if Direct HLW is pursued given the similarities in the control strategy.

\subsection{Basis for Number of Samples for Analyses}

Technology Gap: Analysis of MFPV samples provides the primary means of demonstrating that WAPS parameters for any given batch meet the requirements. For the results to be meaningful, a) the samples must be representative of the product material, and b) the number of replicate 
SRNL-STI-2012-00776

PNNL-22116

Revision 0

samples being analyzed must be adequate to reduce the uncertainty in the glass composition and thereby allow for as broad as possible of a processing envelope. Because of the high resource demands of the product compliance analyses, the number of replicate samples must be chosen carefully, to assure statistical adequacy without extending resource demands beyond capabilities. The current HLW product qualification program calls for single analyses of eight replicate melter feed samples. Based on SRS experience related to DWPF product qualification, analysis of eight sample replicates seems potentially excessive and unwieldy. In contrast, six replicate samples are taken and potentially analyzed with a minimum of four replicates reported in the qualification of DWPF melter feed batches. WTP requires twice as many samples to reduce the composition uncertainty, which translates to a broader processing envelope (the composition uncertainties were found to drop by roughly the square root of the number of samples). However, the sample number and uncertainty size was not optimized. For example, the impact of higher composition uncertainties on the number of HLW glass canisters was not determined.

Approach: SRNL and PNNL will review WTP's product compliance sampling protocol and determine the impact of reducing the number of samples on the composition, property uncertainty, the size of the processing envelope, and the number of projected canisters. If this is not effective, then the laboratories can work with the WTP to determine how to reduce the error sources and provide the basis to reduce the number of samples. Demonstrations during cold commissioning of the vitrification facilities should be used to justify the final number of samples to be taken and analyzed. This effort will be closely coupled with other activities in this section.

Significance/Interfaces: Reduction in the number of product qualification analyses, if appropriate, will result in a significant reduction in laboratory resource demands.

\subsection{Expansion of the Glass Composition Envelope}

Technology Gap: A critical part of the HLW waste form compliance process is the use of the glass composition-property models to identify the blend of waste and glass formers that will meet both process and product performance constraints. The WTP waste form compliance/acceptance process will utilize the most recent HLW glass algorithms to optimize the type and amount of glass forming materials to be mixed with the HLW feed streams in the process described in section 2.3.

The WTP acceptance process for each campaign is limited to assessments based on glass composition-property model predictions within the QGCR and not actual waste glass property measurement. Although this approach has technical merit, the inherent and underlying assumption of the HLW product qualification strategy is that the models apply for each sludge campaign to be processed. This is slightly different than the current approach that is used by DWPF. However, it should be pointed out that when DWPF was starting up there were concerns about model applicability over the projected composition region to be processed in DWPF so the compromise was to ensure applicability of the models for the that sludge batch via a variability study $^{2}$.

The current glass composition-property models used in the HLW glass formulation algorithm ${ }^{33}$ are relatively restricted in the composition region of applicability. To apply those to the full range of expected Hanford HLWs would unnecessarily reduce the waste loading in glass. In fact, current estimate suggest that the resulting glass volume would be roughly double that in current system planning documents. 
Approach: Given the technical foundation of the HLW product compliance program is based on applicability of the glass formulation algorithms to the full range of waste to be processed through WTP, the models should be robust and cover a wide compositional range.

WTP glass composition - property models do exist based on limited baseline flowsheet operations (including anticipated process efficiencies). ${ }^{60}$ Process control models to support radioactive operations at the DWPF operations also exist. However, neither set of models currently cover the full anticipated composition region for WTP HLW glass. ${ }^{\text {ii }}$ Given the anticipated compositional gaps, new data will be required to expand, validate, and refine the existing models; or develop new models in these new compositional regions. Through the development of new data within (and extending beyond) the anticipated HLW compositional region, revised or new models, or individual component limits can be expanded potentially leading to increased waste loadings for HLW feeds.

The proposed research would be to develop glass property data, glass composition-property models, and expanded glass formulation algorithms to cover the full range of anticipated wastes to be processed at WTP with relatively high waste loadings. This program has begun under the management of DOE-ORP and should continue to identify and implement robust algorithms for glass formulation and acceptance. An alternative approach would be to develop glass models for specific compositional areas of interest for a waste type.

Significance/Interfaces: The proposed approach has the potential to impact the effectiveness of the WTP HLW Vitrification Facility, the amount of glass needing to be disposed of, and likely the life-cycle cost at Hanford. The expanded models may be needed before plant startup particularly if the commissioning tank is changed due to the recently identified leak.

\subsection{Potential Change in Repository Requirements and Compliance Programs}

Technology Gap: The Hanford HLW vitrification program, as well as the existing SRS DWPF program, were defined to meet the latest revisions of the requirements of the DOE WAPS, the IICD, MOA for Acceptance of DOE Spent Nuclear Fuel and HLW, and the WASRD. Currently, the DOE has petitioned to withdraw the application to the Nuclear Regulatory Commission for HLW disposition and have begun to consider alternatives. A "Blue Ribbon" panel of experts was convened to evaluate alternative approaches for disposition. The panel has provided recommendations to DOE based on their review ${ }^{61}$ but no definitive plans have been announced by DOE.

Additionally, the current Yucca Mountain legal basis will only allow for 7,000 metric tons of heavy metal (MTHM) worth of DOE HLW ${ }^{\mathrm{iii}}$ and Spent Nuclear Fuel (SNF). As there is nearly twice as much DOE HLW and SNF, there will be a need for an additional disposal option even in the event that the Yucca Mountain repository accepts some DOE HLW.

When the initial HLW compliance programs and plans were written for DWPF and West Valley Demonstration Project (WVDP), U.S. operating experience with vitrification of radioactive glass at large scales did not exist, nor was it extensive internationally. Therefore, some of the

\footnotetext{
ii Note, any waste can be made to fit within the current glass composition if the loading of the waste is reduced enough. However, the resulting waste loadings are so low as the anticipated amount of glass produced with the current WTP HLW models would be double the amount in system planning documents.

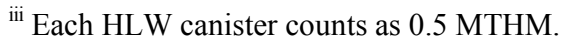


SRNL-STI-2012-00776

PNNL-22116

Revision 0

requirements and associated compliance strategies did not have a strong technical basis and conservatism was included in the requirements as well as in the associated compliance plans from the operating sites. The Hanford WTP has been able to use some of the lessons learned but is still hindered by the comparisons to what other programs have done and has its own suite of regulations from Washington State Department of Ecology. The RW QARD HLW requirements primarily, as well as the additional federal and state regulations, drive the cost of compliance up for HLW vitrification, which in turn has an associated impact on treatment schedule and costs. Reductions in programmatic costs can be obtained by relaxing or eliminating parts or portions of the RW QARD, changing the requirements, or changing the compliance strategy to reduce conservatism and take advantage of the 17 years of production experience.

Approach: Several approaches can be outlined to close this technology gap.

Task 1 - Review Existing Requirements: The national laboratories should review the existing WAPS, WASRD, QA, and facility operating requirements to determine which of the requirements have a strong technical basis with regards to treatment, transportation, storage, and disposal. The national laboratories could then assist in the definition of the appropriate requirements to ensure treatment, storage, transportation and disposal safety for the range of potential disposal options investigated. An example of this might be a change in the environmental conditions for disposal and the associated performance requirements.

For those criteria that were not repository driven, a technical review should also be performed to determine whether the criteria are still applicable or compliance strategies can be changed given the roughly 17 years of radioactive operation at the SRS and experience at the WVDP along with a matured understanding of repository safety drivers. The laboratories could then provide the technical basis to support elimination/change of the non-relevant criteria or alternative approaches to compliance which are more informed from radioactive operations.

Task 2 - Radioactive Qualification Demonstrations: Both the Hanford WTP and SRS DWPF currently require demonstrations of their flowsheets with a radioactive sample before accepting the batch for treatment/immobilization. For SRS, the demonstrations have been performed for 17 years and for 9 different batches. At this point, the chemical reactions that occur during feed preparation in the DWPF are fairly well replicated by simulant testing across a range of conditions and minimal testing with actual sludge samples is performed for glass processing or compliance testing. Therefore, the need for radioactive demonstrations at SRS should be reevaluated based on the available data. As an example, SRNL has already provided the technical basis for the elimination of the fabrication of a glass sample during the qualification process. The compliance program should be modified to determine the analytes of importance and other characteristics of the actual waste than cannot be replicated with simulants (e.g., rheology).

For the Hanford WTP, the discussion in section 4.3 provides a gap analyses and approach for the WTP waste feed qualification program demonstration. This approach would allow more information to be gained before radioactive operations or qualification with the campaign sample, while still allowing the needed analytical information and pertinent process information to be obtained with the campaign sample. Lessons learned from SRS could be incorporated in the strategy to reduce the number of tests and/or provide the details for reducing the qualification program in the future based on a planned collection and evaluation of the process data. Implementation of this approach would require the use of representative simulants and collaboration between the national laboratories, DOE, and the contractors. 
Task 3 - Change in HLW Glass Canister Thickness: Under the existing WAPS, a specification is given for the size of the canisters containing the HLW. Both the SRS and Hanford contractors have expressed interest in reducing the wall thickness on the main body of the canister (not the top head or bottom). This would reduce the amount of material used in fabrication but also allow for an increased volume of glass to be poured in the same sized canister. The Liquid Waste contractor at the SRS has been evaluating this option through a feasibility study, which compares expected production and fabrication changes. Upon its release, the national laboratories could be used to resolve any remaining technical issues with this approach for Hanford and SRS to bring it to closure. It has the potential for significant benefit at Hanford because of the number of canisters to be produced. An alternative approach would be to evaluate the benefit of increasing the canister diameter to $62.5 \mathrm{~cm}$ versus the current nominal $61 \mathrm{~cm}$. These options should then be weighed against each other to determine the pros and cons of each approach.

Task 4 - RW-0333P Quality Assurance Requirements: The HLW vitrification programs currently operate under the quality assurance requirements of RW-0333P. Maintenance of this program is a cost burden to the site contractors, while the sites already maintain a NQA-1 quality assurance program. The RW requirements should be reviewed for applicability to other areas outside of the federal repository such as national and IAEA requirements for exiting treatment, interim, or site storage, and transport across the United States to determine if any reduction in RW-0333P requirements is possible.

Task 5 - Required Analyte Reporting: The potential for elimination or reduction of required analyte reporting was discussed in section 4.2. This has specific application to the measurement and reporting of constituents on the glass waste form particularly where radionuclides are concerned. The requirement to report radionuclides with concentrations equal to or greater than $0.05 \%$ of the activity from the present to 3115 creates significant problems in analyses of the waste and will have no impact on the performance of the glass. An effort to reduce the required analyses, as well as the reporting requirements for out-year projections, should be undertaken in light of the Blue Ribbon Committee recommendations on the repository selection and approval by DOE. The national laboratories could help provide the technical basis for the elimination/reduction.

Task 6 - Reducing Conservatism in HLW Wasteform Compliance: For HLW glasses to be considered acceptable, the durability response as defined by the PCT of the HLW glass in question must be better than the PCT response of the EA glass with the equivalent of two standard deviations confidence. Historically, HLW glasses produced at the DWPF have been an order of magnitude better than the EA glass release with normalized boron release in the range of $1 \mathrm{~g} / \mathrm{L}$. In general, glasses produced in the laboratory for WTP wastes are also highly durable with respect to meeting the EA limit. Given the conservatism between where glasses are currently being formulated and their durability response relative to the EA benchmark and the consideration of a broader range of disposal options, technical inquiries should be made into the potential positive impacts on mission life reduction as one targets glass compositions that are less durable but still meet the current durability requirements. The approaches that could be pursued by the laboratories include updating/refining existing durability models, changing the durability models, and/or defining an alternative compliance approach that still allows the $95 \%$ confidence requirement associated with the EA glass to be met without sacrificing product performance. 
SRNL-STI-2012-00776

PNNL-22116

Revision 0

Significance/Interfaces: This task may significantly streamline the waste form compliance activities. However, the plant can successfully operate without this activity and the potential cost savings are mid-range relative to other tasks being considered in this study. 
SRNL-STI-2012-00776

PNNL-22116

Revision 0

\subsection{Simulant Selection and Development}

The three technical areas require varying degrees of testing before commencement of radioactive operations. The specific program objectives will drive the type of simulant to be used for the testing (see section 2.4 for a description of the simulant types). Selecting the appropriate simulants and development of the protocol to fabricate this simulant to meet the test objectives is a common need for all of the technical areas.

Technology Gap: It is recognized that studies with the best simulants cannot replicate the chemistry and physical properties of the actual waste exactly; therefore, the simulants are often designed to be bounding. Many test programs are thus designed to study trends and define process limitations using simulants, which are then validated using the results from real waste testing. Validation confirms that radioactive operations will be within the bounds defined by the simulant studies. Typically, most research programs err on the side of caution with overly bounding simulants potentially resulting in rejection of valid solutions, over-design of equipment, and/or stalemate (i.e. no solutions are acceptable).

Approach: Three conditions must exist for simulants to be properly designed: 1) An understanding of the physical and chemical properties of the material to be simulated 2) An understanding of the research objectives for the test program utilizing the simulant and 3) An understanding of the simulant material and how preparation techniques impact the finished simulant.

The outline for the roadmap for development of simulants for WTP testing is shown below. It is noted that extensive characterization and developmental work has already been performed in development of simulants for the WTP process. ${ }^{34}$ This effort will utilize the information available from previous work when possible.

Task 1 - Determine the bounding chemical compositions and physical properties of the tank(s) to be simulated based on the expected properties of the material to be transferred to WTP.

a) Evaluate existing tank properties and compositions based on core samples.

b) Obtain additional radioactive samples from tanks that are undergoing slurry retrieval.

c) Determine the impact of tank mixing on physical properties not already defined.

This task is the most difficult to achieve in practice as samples of the actual waste material may not be available. When available, the samples may not be representative of the material to be processed. At Hanford, tank samples are often core samples and may not be representative of the physical properties of the material after the shearing and blending that occurs during waste retrieval.

Task 2 - Determine the properties that will be bounded by the simulant

1) Develop list of selected properties that will be targeted by the WTP waste feed qualification simulants. Existing documents will be used for guidance in selecting the properties that will be targeted. It is noted that it will be difficult to achieve the targeted value for all properties; therefore the properties will be ranked to ensure that the most important properties are targeted first.

2) Evaluate formation of agglomerates in physical and chemical simulants for comparison to the agglomerates formed by the waste as noted in core samples. Chemical simulants of HLW sludge should be expected to form loose agglomerates in a similar manner to the actual tank waste and studies with SRS sludge simulants have indicated that loose agglomerates are formed during quiescent periods. ${ }^{62}$ 
Task 3 - Develop simulant preparation techniques that can produce a prototypic simulant.

1) Create a base simulant using processes that simulate waste generation.

2) SRNL has shown that the preparation method used during simulant production can greatly impact the physical properties produced. ${ }^{63,64,65,66,67}$ It has been shown that the same chemical recipe can produce simulants with low yield stress $(<5 \mathrm{~Pa})$ as well as high yield stress $(>30$ $\mathrm{Pa})$ by changing the temperature, mixing, addition rates, etc. during the precipitation of the metal nitrates. The changes have been shown to impact the particle size as well as the shape of the particle distribution. By altering the parameters used during simulant preparation, a chemical simulant can be made more prototypical of the real waste.

3) Aging (heat treatment), shearing, or otherwise treating simulant to match properties of aged waste.

4) Post-precipitation processes have also been shown to significantly alter the physical properties of chemical simulants and can also impact the speciation of selected species. ${ }^{64,68}$ By using these post-precipitation processes, a chemical simulant can be made more prototypical of the real waste.

5) Evaluation/acceptance of simulant based on selected properties.

6) Evaluation of the primary particle size and degree of agglomeration are expected to be key physical properties to be measured along with rheology and chemical composition.

Significance/Interfaces: Tank farm and WTP operations are being driven by testing that has been performed to date with simulants. If these simulants do not represent actual conditions, operations and product quality will be impacted in the facilities. 
SRNL-STI-2012-00776

PNNL-22116

Revision 0

\subsection{Summary}

The DOE - EM has tasked the SRNL and the PNNL to jointly coordinate the engagement of the broader national laboratory community to bring the scientific and technological rigor needed to evaluate/prioritize alternatives, define/execute technology development opportunities, and inform decisions that will reduce technical and programmatic risks. SRNL and PNNL have a strong knowledge of the EM mission needs and a long history of working with EM, contractors, other national laboratories, universities, and regulators to develop and deploy successful alternative approaches to many of EM's most challenging technical issues. Through a series of meetings amongst the national laboratories, site field offices and site contractors, the initiative area of Hanford Tank Waste Feed Acceptance and Product Qualification was selected for further followup. This document provides a summary of the activities performed to date by the WFA\&PQ team in assessing the existing Tank Farm and WTP waste acceptance criteria and HLW product qualification requirements and strategies to determine if any risk reduction or cost and schedule benefits could be obtained.

The team review identified three broad technical areas, which were 1) Feed Criteria Development, 2) WTP Process Qualification, and 3) HLW Product Qualification. Simulant Development was a common challenge and need for all of the technical areas. Each of these areas was reviewed for technology gaps or improvement opportunities. Technology approaches were identified for closing the gaps or implementing the opportunities and an initial assessment of the significance/interfaces of each approach was performed. A summary of the technology gaps or improvement opportunities are provided in the table below.

Revisions to this assessment will be performed as programs are completed by both the laboratories and the contractors providing support to the Hanford Tank Waste Treatment and Immobilization Plant. 


\begin{tabular}{|c|c|}
\hline Section & Technology Gap/Improvement Opportunity \\
\hline \multirow{5}{*}{$\begin{array}{l}3.1 \text { - Understanding Properties of the } \\
\text { Feed }\end{array}$} & Parameters Controlling Waste Feed Rheology \\
\hline & Particle Size and Density \\
\hline & Critical Velocity \\
\hline & Slurry Abrasivity, Erosion, and Corrosion Assessments \\
\hline & Physical and Chemical Speciation of Plutonium \\
\hline \multirow{3}{*}{$\begin{array}{lll}3.2 \quad- & \text { Understanding } & \text { Process } \\
\text { Requirements } & & \end{array}$} & Scaling of Demonstration Tests \\
\hline & Modeling of Non-Newtonian Fluids \\
\hline & Process Performance with Polydisperse Solids \\
\hline \multirow[t]{5}{*}{$\begin{array}{l}3.3 \text { - Conditioning of Waste in the Tank } \\
\text { Farm or within WTP }\end{array}$} & $\begin{array}{l}\text { Size Reduction or Separation Techniques to Reduce or } \\
\text { Remove Large Particles }\end{array}$ \\
\hline & Enhanced Mixing Systems for Staging Feed \\
\hline & $\begin{array}{l}\text { Washing or Pretreatment of HLW Sludge in the Tank } \\
\text { Farm }\end{array}$ \\
\hline & Al Dissolution in the Tank Farm and Pretreatment Facility \\
\hline & Waste Feed Rheology Control \\
\hline \multirow[t]{3}{*}{$\begin{array}{l}4.1 \text { - Representative Sampling of the Feed } \\
\text { Staging Tank and Process Vessels }\end{array}$} & $\begin{array}{l}\text { Unknown Sample Size for Waste Feed Qualification } \\
\text { Program }\end{array}$ \\
\hline & $\begin{array}{l}\text { Representative Sampling for Waste Feed Qualification } \\
\text { Program }\end{array}$ \\
\hline & $\begin{array}{l}\text { Isolok }^{\circledR} \text { Sampling System for Obtaining the Waste Feed } \\
\text { Qualification and Vessel Samples }\end{array}$ \\
\hline \multirow{3}{*}{$\begin{array}{l}4.2 \text { - Waste Acceptance Criteria/DQO } \\
\text { Analyses of Staged Feed }\end{array}$} & Extensive Analytical Requirements \\
\hline & Analytical Gaps and Improvements \\
\hline & Hydrogen Generation Rate Measurement \\
\hline \multirow{2}{*}{$\begin{array}{l}4.3 \text { - Process Qualification Program with } \\
\text { Waste Feed Qualification Sample }\end{array}$} & Pretreatment Process Demonstration \\
\hline & $\begin{array}{l}\text { Elimination of Glass Analyses Post Glass Former Addition } \\
\text { in the Waste Feed Qualification Process }\end{array}$ \\
\hline $\begin{array}{l}5.1 \text { - Use of VSL-HLP-0027/0028 for } \\
\text { HLW Product Qualification }\end{array}$ & $\begin{array}{l}\text { Develop, Demonstrate, and Implement Strategy to } \\
\text { Demonstrate Homogenous Mixing }\end{array}$ \\
\hline $\begin{array}{l}5.2 \text { - Basis for Number of Samples for } \\
\text { Analyses }\end{array}$ & $\begin{array}{l}\text { Review the Basis for Number of Samples and Recommend } \\
\text { Changes as Necessary }\end{array}$ \\
\hline \multirow[t]{2}{*}{$\begin{array}{l}5.3 \text { - Expansion of the Glass Composition } \\
\text { Envelope }\end{array}$} & $\begin{array}{l}\text { Broaden the Existing Glass Models to Cover Full Range of } \\
\text { Anticipated WTP Wastes }\end{array}$ \\
\hline & $\begin{array}{l}\text { Develop Glass Models for Specific Compositional Areas } \\
\text { by Waste Type }\end{array}$ \\
\hline \multirow{6}{*}{$\begin{array}{l}5.4 \text { - Potential Change in Repository } \\
\text { Requirements and Compliance Programs }\end{array}$} & Review Existing Requirements \\
\hline & Radioactive Qualification Demonstrations \\
\hline & Change in HLW Glass Canister Thickness \\
\hline & RW-0333P Quality Assurance Requirements \\
\hline & Required Analyte Reporting \\
\hline & Reducing Conservatism in HLW Wasteform Compliance \\
\hline \multirow[t]{3}{*}{$\begin{array}{l}\text { 6.0 - Simulant Selection and } \\
\text { Development }\end{array}$} & $\begin{array}{l}\text { Determine Bounding Chemical Compositions and Physical } \\
\text { Properties }\end{array}$ \\
\hline & Determine Properties to be Bounded by the Simulant \\
\hline & Develop Simulant Preparation Techniques \\
\hline
\end{tabular}




\subsection{References}

1 C.L. Leung, E.J. Slaathaug, C. Seidel, D. Greer, Y. Rasmussen, and M. Thien, One System Initial Gap Analysis between Waste Treatment Plant Waste Acceptance Criteria and Tank Farm Sampling and Transfer Capability, 2010-2 Implementation Plan Commitment 5.5.3.1, RPP-RPT-53343, Revision 0, River Protection Project, Waste Treatment Plant, Richland, WA (2012).

2 J.W. Ray, B.H. Culbertson, S.L. Marra and M.J. Plodinec, DWPF Glass Product Control Program, WSRC-IM-91-116-6, Revision 7, Savannah River Site, Aiken, SC (2012).

3 C.M. Jantzen, J.B. Pickett, K.G. Brown, T.B. Edwards, and D.C. Beam, "Process/Product Models for the Defense Waste Processing Facility (DWPF): Part I. Predicting Glass Durability from Composition Using a Thermodynamic Hydration Energy Reaction Model (THERMO), WSRC-TR-93-672, Revision 1, Savannah River Site, Aiken, SC (1995).

4 K.G. Brown, R.L. Postles, and T.B. Edwards, SME Acceptability Determination for DWPF Process Control, WSRC-TR-95-00364, Revision 5, Savannah River Site, Aiken, SC (2006).

5 Office of Environmental Management, Waste Acceptance Product Specifications for Vitrified High Level-Waste Forms, DOE/EM-0093, Revision 3, US Department of Energy, Washington, DC (2012).

A.V. Arakali, D.L. Banning, P.A. Benson, and D.A. Greer, Initial Data Quality Objectives for WTP Feed Acceptance Criteria, 24590-WTP-RPT-MGT-11-014, Revision 0, Bechtel, Richland, WA (2011). J.W. Olson, ICD-19 - Interface Control Document for Waste Feed, 24590-WTP-ICDMG-01-019, Revision 5, Waste Treatment Plant, Richland, WA (2011). D.A. Dodd and A.V. Arakali, Integrated Sampling and Analysis Requirements Document (ISARD), 24590-WTP-PL-PR-04-0001, Revision 2, Waste Treatment Plan, Richland, WA (2008). A.V. Arakali, D. Blumenkranz, J.L. Meehan, L.A. Huffman, and J. Yokel, Regulatory Data Quality Objectives Optimization Report, 24590-WTP-RPT-MGT-04-001, Revision 0, River Protection Project, Waste Treatment Plant, Richland, WA (2004). M.G. Thien, et al., Waste Feed Delivery Mixing and Sampling Program Plan and Test Requirements, RPP-PLAN-41807, Washington River Protection Solutions, LLC., Richland, WA (2012). M.G. Thien, V.L. Jackson, and C.C. Haas, Tank Waste Mixing and Sampling Update, RPP-50557, Revision 0, Washington River Protection Solutions, LLC., Richland, WA (2011).

M.R. Duignan et al., Solids Accumulation Scouting Studies, SRNL-STI-2012-00508, Savannah River National Laboratory, Aiken, SC (2012).

K.M. Denslow, J.R. Bontha, H.E. Adkins, J.J. Jenks, and D.F. Hopkins, Hanford Tank Farms Waste Feed Flow Loop Phase VI: PulseEcho System Performance Evaluation, PNNL-22029, Pacific Northwest National Laboratory, Richland, WA (2012). I. Papp, Low Order Accumulation Model Testing with Non-Newtonian Vessel Arrangement, 24590-WTP-RPT-ENG-11-013, Waste Treatment Plant, Richland, WA (2011).

15 I. Papp, Integrated Pulse Jet Mixed Vessel Design and Control Strategy, 24590-WTPRPT-ENG-10-001, Revision 1, Waste Treatment Plant, Richland, WA (2011). 
J.R. Bontha, J.M. Bates, C.W. Enderlin, and M.G. Dodson, Large Tank Experimental Data for Validation of the FLUENT CFD Model of Pulsed Jet Mixers, PNWD-3303, WTP-RPT-081, Revision 0, WTP Project Report, Richland, WA (2003).

J.P. Henschel, Report of External Flowsheet Review Team for the Hanford Tank Waste Treatment and Immobilization Plant - Final Report Titled: Comprehensive Review of the Hanford Waste Treatment Plant Flowsheet and Throughput, CCN 132846, River Protection Project, Waste Treatment Plant, Richland, WA (2006).

P.A. Meyer, J.A. Bamberger, C.W. Enderlin, J.A. Fort, B.E. Wells, S.K. Sundaram, P.A. Scott, M.J. Minette, G.L. Smith, C.A. Burns, M.S. Greenwood, G.P. Morgan, E.B.K. Baer, S.F. Snyder, M. White, G.F. Piepel, B.G. Amidan, and A. Heredia-Langner, Pulse Jet Mixing Tests With Noncohesive Solids, PNNL-18098, WTP-RPT-182, Revision 0, Pacific Northwest National Laboratory, Richland, WA (2009).

I. Papp, EFRT Issue M3 PJM Vessel Mixing Assessment, Volume 1, 24590-WTPRPT-ENG-08-021-01, Revision 1, Waste Treatment Plant, Richland, WA (2010).

Defense Nuclear Facility Safety Board, Department of Energy Plan to Address Waste Treatment and Immobilization Plant Vessel Mixing Issue, Implementation Plan for DNFSB 2010-2 (2011).

D.C. Koopman, C.J. Martino, and M.R. Poirier, Properties Important to Mixing for WTP Large Scale Integrated Testing, SRNL-STI-2012-00062, Savannah River National Laboratory, Aiken, SC (2012).

I. Papp, EFRT Issue M3 PJM Vessel Mixing Assessment, Volume 1 of, 24590-WTPRPT-ENG-08-021-01, Revision 1, Waste Treatment Plant, Richland, WA (2010).

T. Campbell, Integrated Pulse Jet Mixed Vessel Design and Control Strategy, 24590WTP-RPT-ENG-10-001, Revision 1, Waste Treatment Plant, Richland, WA (2011).

P.A. Benson and T. Halverson, Waste Feed Qualification Program Plan, 24590-WTPPL-OP-12-0004, Revision 0, Bechtel, Richland, WA (2013).

D.K. Peeler, et. al., SRNL Phase 1 Assessment of the WAC/DQO and Unit Operations for the WTP Waste Qualification Program, SRNL-STI-2011-00724, Savannah River National Laboratory, Aiken, SC (2012).

E. Slaathaug, Procedure to Determine the Waste Feed Treatment Approach, 24590WTP-PET-11-002, Bechtel, River Protection Project, Waste Treatment Plant, Richland, WA (2011).

Office of Civilian Radioactive Waste Management, Waste Acceptance System Requirements Document, DOE/RW-0351, Revision 5, US Department of Energy, Washington, DC (2008),

US Department of Energy, Office of Civilian Radioactive Waste Management, Integrated Interface Control Document, DOE/RW-0511, Volume 1, Revision 4, US Department of Energy, Washington, DC (2008).

US Department of Energy, Memorandum of Agreement for Acceptance of Spent Nuclear Fuel and High-Level Waste between the Assistant Secretary for Environmental Management (EM) U.S. Department of Energy (DOE), Washington, D.C. and the Director Office of Civilian Radioactive Waste Management (RW) U.S. DOE, Washington, D.C., Revision 2 (2007).

US Department of Energy, Hanford Tank Waste Treatment and Immobilization Plant, DOE Contract DE-AC27-01RV14136, Section C, Richland, WA (2000).

J. Nelson and J. Vienna, IHLW Waste Form Compliance Plan for the Hanford Tank Waste Treatment and Immobilization Plant, 24590-HLW-PL-RT-07-0001, Revision 3, Waste Treatment Plant, Richland, WA (2009). 
SRNL-STI-2012-00776

PNNL-22116

Revision 0

J. Nelson, IHLW Waste Form Qualification Report for the Hanford Tank Waste Treatment and Immobilization Plant - Introduction, 24590-HLW-RPT-RT-08-001, Revision 0, Waste Treatment Plant, Richland, WA (2010).

J.D. Vienna and D.S. Kim, Preliminary IHLW Formulation Algorithm Description, 24590-HLW-RPT-RT-05-001, Revision 0, River Protection Project, Waste Treatment Plant, Richland, WA (2008).

B.E. Wells, Y. Onishi, C.A. Burns, R.C.Daniel, D.E. Kurath, J.L. Huckaby, E.C. Buck, K.K. Anderson, L.A. Mahoney, S.K. Cooley, and J.M. Tingey, Hanford Waste Physical and Rheological Properties: Data and Gaps, PNNL-20646, Pacific Northwest National Laboratory, Richland, WA (2011).

C.J. Bannochie, J.M. Pareizs, and D.C. Koopman, Sludge Batch 2/3 Blend SRAT Cycle in the SRNL Shielded Cell, WSRC-TR-2004-00097, Savannah River Site, Aiken, SC (2004).

B.E. Wells, P.A. Gauglitz, and D.R. Rector, Comparison of Waste Feed Delivery Small Scale Mixing Demonstration Simulant to Hanford Waste, PNNL-20637, Revision 2, Pacific Northwest National Laboratory, Richland, WA (2012).

K.P. Lee, B.E. Wells, P.A. Gauglitz, and R.A. Sexton, Waste Feed Delivery Mixing and Sampling Program Simulant Definition for Tank Farm Performance Testing, RPPPLAN-51625, Revision 0, Washington River Protection Solutions LLC, Richland, WA (2012).

M.S. Fountain, J. Blanchard, R.L. Erikson, D.E. Kurath, and D.T. Howe, "Design of a Particle Shadowgraph Velocimetry and Size (PSVS) System to Determine Particle Size and Density Distributions in Hanford Nuclear Tank Wastes", WM2012 Conference, February 26 - March 1, 2012, Phoenix, AZ.

M.R. Duignan, et al., RPP-WTP Slurry Wear Evaluation: Slurry Abrasivity, WSRCTR-2002-00062, Savannah River Site, Aiken, SC (2002).

A.B. Carlson, P.J. Certa, T.M. Hohl, J.R. Bellomy III, T.W. Crawford, D.C. Hedengren, A.M. Templeton, H.S. Fisher, S.J. Greenwood, D.G. Douglas, and W.J. Ulbright Jr, Test Report, 241-AZ-101 Mixer Pump Test, RPP-6548, Revision 1, Numatec Hanford Corporation, Richland, WA (2001).

A.P. Poloski, S.T. Arm, J.A. Bamberger, B. Barnett, R. Brown, B.J. Cook, C.W. Enderlin, M.S. Fountain, M. Friedrich, B.G. Fritz, R.P. Mueller, F. Nigl, Y. Onishi, L.A. Schienbein, L.A. Snow, S. Tzemos, M. White, and J.A. Vucelick, Technical Basis for Scaling of Air Sparging Systems for Mixing in Non-Newtonian Slurries, PNWD3541, WTP-RPT-129, Revision 0, Battelle-Pacific Northwest Division, Richland, WA (2005).

E.L. Paul, V.A. Atiemo-Obeng, and S.M. Kresta, Handbook of Industrial Mixing Science and Practice, John Wiley \& Sons, Inc., Hoboken, NJ (2004).

Presentation by I. Ayranci, T. Ng, A.W. Etchells, and S. Kresta, "A Design Rule for Prediction of the Just Suspended Speed of Mixed Slurries”, AIChE Meeting, October 17, 2011.

A.P. Poloski, H.E. Adkins, J. Abrefah, A.M. Casella, R.E. Hohimer, F. Nigl, M.J. Minette, J.J. Toth, J.M. Tingey, and S.T. Yokuda, Deposition Velocities of Newtonian and Non-Newtonian Slurries in Pipelines, PNNL-17639, WTP-RPT-175, Revision 0, Pacific Northwest National Laboratory, Richland, WA (2009).

J.R. Bontha, H.E. Adkins, K.M. Denslow, J.J. Jenks, C.A. Burns, P.P. Schonewill, G.P. Morgen, M.S. Greenwood, J. Blanchard, T.J. Peters, P.J. Macfarlan, E.B. Baer, and W.A. Wilcox, Test Loop Demonstration and Evaluation of Slurry Transfer Line Critical 
Velocity Measurement Instruments, PNNL-19441, Revision 0, Pacific Northwest National Laboratory, Richland, WA (2010).

B.V. Churnetski, Effective Cleaning Radius Studies, DPST-81-282, Savannah River Site, Aiken, SC (1981).

M.R. Powell, Y. Onishi, and R. Shekarriz, Research on Jet Mixing of Settled Sludges in Nuclear Waste Tanks at Hanford and Other DOE Sites: A Historical Perspective", PNL-11686, Pacific Northwest National Laboratory, Richland, WA (1997).

J.G. Van De Vusse, "Vergleichende Ruhrversuche zum mischen loslicher Flussigkeiten 12000m³ Behalter", Chem. Ing. Tech., 31:583-587 (1959).

H. Fossett and L.E. Prosser, "The Application of Free Jets to Mixing of Fluids in Bulk", Proc. I. Mech. E., 160:224-232 (1949).

N. Okita and Y. Oyama, "Mixing Characteristics in Jet Mixing", Kagaku Koguka, 27:252-259 (1963).

E.A. Fox and V.E. Vex, "Single Phase Blending of Liquids", A. I. Ch. E. J., 2:539-544 (1956).

J.W. Hiby and M. Modigell, "Experiments on Jet Agitation", 6th CHISA Conf., Prague, (1978).

R. Grenville and J. Tilton, "A New Theory Improves the Correlation of Blend Time Data from Turbulent Jet Mixed Vessels", Trans. Inst. of Chem. Eng., Vol. 74, (1996),

R.A. Leishear, M.R. Poirier, and M.D. Fowley, Blending Study for SRR Salt Disposition Integration: Tank 50H Scale-Modeling and Computer-Modeling for Blending Pump Design, Phase 2, SRNL-STI-2010-00151, Savannah River National Laboratory, Aiken, SC (2011).

W.B. Van Pelt, Dr. David Dickey Consultation on Mixing for $2 \mathrm{H}$ Evaporator Cleaning and Restart, WSRC-TR-2000-00439, Savannah River Site, Aiken, SC (2000).

J. Chun, A.P. Poloski, and E.K. Hansen, "Stabilization and Control of Rheological Properties of $\mathrm{Fe}_{2} \mathrm{O}_{3} / \mathrm{Al}(\mathrm{OH})_{3}$-rich Coloidal Slurries under High Ionic Strength and $\mathrm{pH}$ ", Journal of Colloids and Interface Science, 348: 280-288 (2010).

G.M. Duncan, Partial Response to Condition of Acceptance Item 2.3 on Evaluation of Uncertainty in the WTP Hydrogen Generation Rate Correlation, CCN-142843, Waste Treatment Plant, Richland, WA (2009).

D.K. Peeler, E.K. Hansen, C.C. Herman, S.L. Marra, and W.R. Wilmarth, SRNL Phase 1 Assessment of the WTP Waste Qualification Program, SRNL-STI-2011-00723, Savannah River National Laboratory, Aiken, SC (2012).

A.V. Arakali, J.C. Jain, and D.A. Dodd, Plan for WTP Feed Pre-qualification, 24590WTP-PL-OP-07-0001, Revision 1, River Protection Project, Waste Treatment Plant, Richland, WA (2008).

G.F. Piepel et al., IHLW PCT, Spinel T1\%, Electrical Conductivity, and Viscosity Model Development, VSL-07R1240-4, Vitreous State Laboratory, The Catholic University of America, Washington, DC (2008).

L.H. Hamilton, B. Scowcroft, M.H. Ayers, V.A. Bailey, A. Carnesale, P.V. Domenici, S. Eisenhower, C. Hagel, J. Lash, A.M. Macfarlane, R.A. Meserve, E.J. Moniz, P.F. Peterson, J.W. Rowe, and P. Sharp. Blue Ribbon Commission on America's Nuclear Future: Report to the Secretary of Energy, Blue Ribbon Commission on America's Nuclear Future (BRC), Washington, DC, (2012).

A.R. Marinik, Development of a Suitable Dispersion Agent for DWPF, SRNL-GPD2004-00052, Savannah River Site, Aiken, SC (2004). 

DWPF Sludge Batch 3 Simulant, WSRC-TR-2004-00578, Savannah River Site, Aiken, SC (2004).

D.C. Koopman and R.E. Eibling, Preparation and Heat-Treatment of DWPF Simulants with and without Co-precipitated Noble Metals, WSRC-TR-2005-00285, Savannah River Site, Aiken, SC (2005).

D.C. Koopman, D.P. Lambert, D.R. Best, and M. J. Barnes, Rheology Improvements during Preparation of 40-inch Heel Case Simulants for Sludge Batch 4, WSRC-STI2006-00067, Savannah River Site, Aiken, SC (2006).

D.C. Koopman, D.P. Lambert, and M. J. Barnes, Preparation of Sludge Batch 4 Qualification Simulants for DWPF Process Simulations, WSRC-STI-2006-00242, Savannah River Site, Aiken, SC (2006).

J.D. Newell, D.P. Lambert, M.E. Stone, and A.I. Fernandez, Continuously Stirred Tank Reactor Parameters That Affect Sludge Batch 6 Simulant Properties, SRNL-STI2009-00603, Savannah River Site, Aiken, SC (2009).

D.C. Koopman, Evaluation of Potential Foaminess in Sludge Batch 5 Simulants, SRNL-L3100-2008-00001, Savannah River Site, Aiken, SC (2008). 


\section{Distribution:}

US Department of Energy

K.D. Gerdes

M.A. Gilbertson

D. Koutsandreas

N.P. Machara

K.G. Picha

J.E. Rhoderick

S.P. Schneider

T.A. Shrader

A.C. Williams

US Department of Energy - Office of River

Protection

D.H. Alexander

S.L. Charboneau

J.A. Diediker

T.W. Fletcher

B.J. Harp

C.C. Harrington

A. Kruger

Waste Treatment Plant

A.V. Arakali

P.A. Benson

G.M. Duncan

M.R. Hamlet

J. Markillie

J.L. Nelson

I.G. Papp

D.R. Reinem

Washington River Protection Solutions

S.T. Arm

P.A. Cavanah

T.W. Crawford

J.M. Frye

J.G. Reynolds

P.L. Rutland

S.A. Saunders

L.E. Thompson
Savannah River National Laboratory

D.J. Adamson

C.J. Bannochie

T.B. Brown

M.J. Cercy

D.R. Click

T.B. Edwards

S.D. Fink

J.C. Griffin

E.K. Hansen

K.R. Hera

C.C. Herman

D.T. Herman

E.N. Hoffman

S.L. Marra

D.J. McCabe

D.K. Peeler

R.R. Pelfrey

F.M. Pennebaker

M.R. Poirier

S.H. Reboul

M.E. Stone

W.R. Wilmarth

J.E. Young

Pacific Northwest National Laboratory

P.R. Bredt

C.F. Brown

J. Chun

J.A. Fort

R.A. Peterson

G.L. Smith

J.D. Vienna

B.E. Wells

Savannah River Remediation

J.W. Ray

J. Tseng 